\title{
Creating a Multilateral Wealth Fund for a Global Public Good: Proposed Approach to Assessing Performance and Awarding Returns for a Tropical Forest Finance Facility
}

\author{
Michael Wolosin, Michele de Nevers, Kenneth Lay, and \\ Patricia Bliss-Guest
}

\begin{abstract}
The Tropical Forest Finance Facility is a proposal to establish a pay-for-performance mechanism to finance reduced deforestation of tropical forests. The proposal would maximize the efficient use of public credit and builds on major technology breakthroughs for measuring results. This paper proposes a logical framework for understanding the current landscape of international forest finance to explore options for the potential role of the TFFF, and recommends pursuing it as a tropical forest public goods facility to support both development objectives and global public goods objectives. It explains proposed options for assessing performance and allocating returns to the TFFF to achieve these objectives.
\end{abstract}




\title{
Creating a Multilateral Wealth Fund for a Global Public Good: Proposed Approach to Assessing Performance and Awarding Returns for a Tropical Forest Finance Facility
}

\author{
Michael Wolosin, Michele de Nevers, Kenneth Lay, \\ and Patricia Bliss-Guest*
}

* Michael Wolosin is the president of Forest Climate Analytics, Michele de Nevers is a senior associate at the Center for Global Development, Kenneth Lay is a principal at Priority Transactions Group LLC and the former vice president and treasurer of the World Bank, and Patricia BlissGuest is a consultant for Priority Transactions Group LLC and the former senior manager of the Climate Investment Funds.

The authors would like to thank reviewers Anit Mukherjee and Nancy Harris; participants in a roundtable discussion on technical aspects of this proposal including Jim Baker, Josefina Braña-Varela, Jonah Busch, Patricia Elias, Peter Graham, and Frances Seymour; and forest experts who have engaged in thoughtful conversations about the measurement and monitoring aspects of this proposal over the past few years including Keith Andersen, Alessandro Baccini, Crystal Davis, Christiane Ehringhaus, Scott Goetz, Matt Hansen, Werner Kornexl, Ruben Lubowski, Maarten van der Eynden, and too many others to name.

Any remaining errors are our full responsibility.

The Center for Global Development is grateful for contributions from the Rockefeller Foundation and the Norwegian Agency for Development Cooperation in support of this work.

Michael Wolosin, Michele de Nevers, Kenneth Lay, and Patricia Bliss-Guest. 2018. "Creating a Multilateral Wealth Fund for a Global Public Good: Proposed Approach to Assessing Performance and Awarding Returns for a Tropical Forest Finance Facility." CGD Working Paper. Washington, DC: Center for Global Development. https://www. cgdev.org/publication/creating-multilateral-wealth-fund-global-public-good-proposedapproach-assessing

Center for Global Development 2055 L Street NW Washington, DC 20036

202.416.4000

(f) 202.416 .4050

www.cgdev.org
The Center for Global Development is an independent, nonprofit policy research organization dedicated to reducing global poverty and inequality and to making globalization work for the poor. Use and dissemination of this Working Paper is encouraged; however, reproduced copies may not be used for commercial purposes. Further usage is permitted under the terms of the Creative Commons License.

The views expressed in CGD Working Papers are those of the authors and should not be attributed to the board of directors, funders of the Center for Global Development, or the authors' respective organizations. 


\section{Note}

Note: This paper is one of four related papers. The overarching paper, "Creating a Multilateral Wealth Fund for a Global Public Good: A Proposal for a Tropical Forest Financing Facility," presents a summary of all the details about all the components of the proposal. Three complementary papers focus in depth on the core elements of the proposal related to: financing strategy, performance assessment and allocation of investment returns (the current paper), and governance arrangements, respectively. For the reader's ease, each subsidiary paper includes a brief summary of the overall proposal. 


\section{Contents}

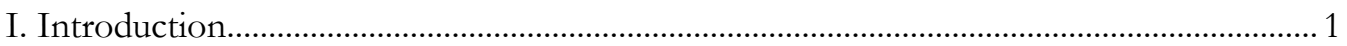

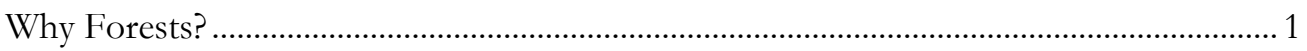

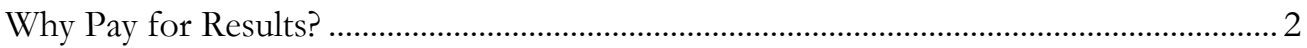

II. Overview: A Proposal for a Tropical Forest Finance Facility ............................................. 4

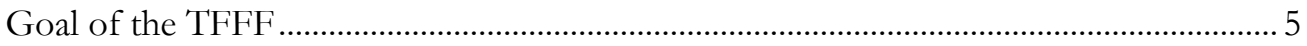

TFFF's Financing Strategy …………………………….............................................. 5

Governance Arrangements for the TFFF ....................................................................... 7

III. International Forest Finance and the TFFF ………………........................................

The Current Landscape of Forest Finance............................................................................ 10

Potential Roles for the TFFF............................................................................................ 14

IV. Performance Assessment and Rewards Allocation...........................................................2 21

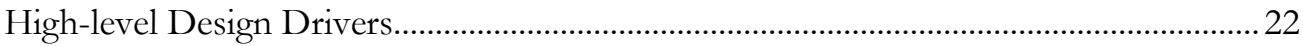

Monitoring Data ………………………………………............................................... 24

Baselines (Reference Levels) ....................................................................................... 31

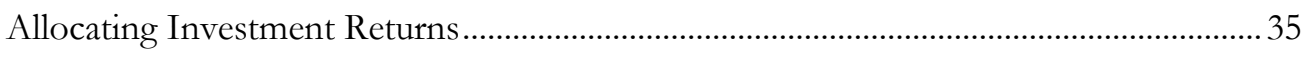

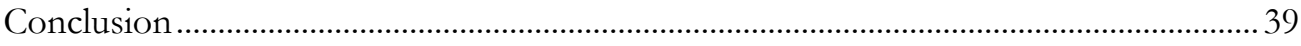

Annex 1: Proposed Performance Assessment and Allocation Functions.............................. 40

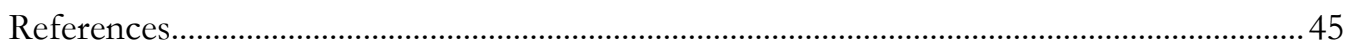




\section{Introduction}

Reaching the Sustainable Development Goals will require new investments estimated well into the trillions of dollars annually, ${ }^{1}$ an order of magnitude greater than total global annual foreign aid. This investment will be needed in traditional development sectors, such as education and health, as well as in global public goods like climate change mitigation.

Given the scale of the challenge, there is a keen recognition that public sector funding will not be sufficient to achieve the SDGs, and scarce public resources must be leveraged effectively to deliver development returns. Recognizing the strains on national budgets and new demands on foreign assistance and public climate change finance, CGD's work in sustainable development finance explores how to maximize the efficient use of public credit and to structure effective partnerships between public and private investors.

Catalyzing "massive transformative investments" 2 is at the heart of the discourse on sustainable development and global public goods.

This paper sets forth an innovative financing proposal aimed at addressing a critical environment and development challenge: reducing the loss of tropical forests, both for national development benefits and to promote the global public goods they provide, including biodiversity and climate mitigation. The proposed financing mechanism would generate substantial resources to provide an incentive for action to halt deforestation without encumbering national budgets nor drawing on foreign aid budgets.

The proposal is to establish a long-term investment fund, akin to a multilateral sovereign wealth fund. Investors (sovereigns and private investors) would provide low-cost loans to the fund, which would then be invested in a diversified portfolio of higher-return assets. Drawing on CGD's work on Cash-on-Delivery aid, the excess returns on the investment fund, above the cost of the loans and fund management, would be used to reward tropical forest countries for their successful performance in reducing deforestation. While the proposal outlined here utilizes an innovative financing mechanism to address environmental goals, the ideas could as well be applied to other sustainable development priorities and global challenges.

\section{Why Forests?}

Healthy forests are a cornerstone of sustainable economic growth across the tropics. Halting and reversing tropical forest loss would yield large-scale development and ecosystem service

\footnotetext{
1 "From Billions to Trillions" (2015).

${ }^{2}$ Kristalina Georgieva, "Why and How Change is Coming to the World Bank," interview with Rajesh Mirchandani, Center for Global Development, podcast audio, April 13, 2017, https://www.cgdev.org/media/whyand-how-change-coming-world-bank-new-ceo-kristalina-georgieva
} 
benefits, including protecting biodiversity, local and global water cycling, reduced flooding and landslides, health, food, and pollination.

Furthermore, local communities and indigenous peoples often depend on forests for their livelihoods, health, food security, culture, and safety. Ecosystem approaches, including the maintenance of forest cover, can also strengthen resilience and adaptation to climate change. Maintaining forests and other ecosystems to buffer the impacts of climate change is often less costly than having to replace lost ecosystem functions through infrastructure or technology.

Although tropical forests generate both local development benefits and global public goods, such as biodiversity and climate mitigation, tropical forest countries face significant political and economic pressures to convert forest lands to other uses. Cleared forest land often can be "repurposed" for agriculture or other uses that quickly produce steady streams of muchneeded income for individuals, businesses, local communities, and provincial and national governments. Globally, the annual rate of deforestation remains unacceptably high, with an area the size of Austria being cleared every year. Unless deforestation is halted, it is likely that an area the size of India will be lost by 2050 .

\section{Why Pay for Results?}

\section{The Development Case}

Results-based payment approaches focus on structuring incentives to change behavior. CGD has carried out research and developed policy advice on results-based approaches in a range of sectors. An extension of these ideas, Cash-on-Delivery (COD) aid, aims to change the behavior not just of recipients but also of funders. COD aid provides funding for the achievement of results aimed at addressing constraints to development at the national level. COD aid differs from other programs in that it eschews the imposition of preconditions and does not require agreements between funders and recipients on strategies to achieve results. The only "preconditions" relevant to COD aid are a good measure of progress and a credible way to verify it.

One of the key features of COD aid is that the funder embraces a hands-off approach, emphasizing country ownership and the power of incentives to drive outcomes, rather than financing projects that provide guidance or technical assistance. Many tropical forest countries may lack capacity to deliver results; TFFF may provide an additional incentive for these countries to fully utilize, invest in, and seek success on capacity-building work that may be financed by the various traditional mechanisms of support. Building on the goals articulated in the 2005 Paris Declaration on Aid Effectiveness, COD aid aims to foster accountability among funders, recipients and their constituents, build local ownership and rely on local institutions, permit learning by doing, experimentation and assessment. Without information about whether goals are being met, it is difficult to determine whether programs are successful. COD aid also seeks to attract new funders, including private sources, enable 
better funder coordination, reduce administrative and reporting burdens and generally promote the expansion of aid.

Under the COD aid model, at no point does the funder specify or monitor inputs. Similarly, the funder does not impose conditions or restrictions on the use of funds (rewards payments). It provides recipient countries with full authority and flexibility to undertake interventions or address policy issues that will lead to the desired results, even if such interventions and policies are outside the domain of the relevant sector ministry or subnational government entity. It does this by recognizing and further encouraging the recipient country's inherent ownership and responsibility over strategies and implementation, and then paying for measured and verified results.

\section{Results-Based Payments for Forests}

A major incentive is needed to encourage the governments of the countries in which tropical forests are located to protect and conserve them. With the exception of a few large bilateral programs between Norway and countries with large forest resources, until now, almost all the money spent by governments and aid organizations to reduce deforestation is channeled through traditional aid approaches that focus on inputs such as technical assistance for "readiness," analytical studies, project-based financing and staff salaries, rather than paying for actual results—-reduced forest loss. Toward this end, CGD has been working with tropical forest countries and potential investors to create a multilateral wealth fund, similar to a sovereign wealth fund (SWF), whose proceeds, after costs, would reward tropical forest countries for their results in reducing deforestation and protecting forests.

Forests lend themselves to pay-for-performance funding approaches because recent advances in satellite monitoring technology make results measurement relatively straightforward, transparent and consistent, compared to other sectors where there may be less agreement on outcomes and performance measures, and where assessing outcomes would require expensive on-the-ground surveys.

In the case of forests and climate, a results-based payments mechanism called REDD+ has been developed through more than a decade of efforts by dedicated professionals around the world under the aegis of the UNFCCC. This framework for international partnerships to support forest country efforts to protect and enhance forests has been codified and embodied in a series of international climate agreements, including most recently the sections relating to REDD+ in the Paris Climate Agreement. The idea is that by offering serious and reliable funding to reward successful efforts to reduce deforestation, a major incentive can be provided to developing countries to move forward with the necessary actions.

Like COD aid, REDD+ recognizes that macro decisions that are in the purview of national governments, such as prices, taxes, and land use policies, shape actions on the ground and that the problem of deforestation cannot be addressed simply by building capacity and enforcement at the local level. A large and visible payment for reducing deforestation can help to strengthen public institutions and motivate politicians, not just technocrats, 
triggering helpful changes in political and bureaucratic arrangements. The incentive payment complements conventional forest assistance programs and motivates countries to draw on the range of other forest finance programs already in place (FCPF, Profor, UN REDD+, etc.).

While there is widespread agreement that a financial incentive to tropical forest countries to reduce deforestation is essential, until now, the large-scale, results-based finance initially envisioned for REDD+ has yet not materialized. Finance for forests in tropical forest countries accounts for less than 2 percent of global mitigation-related development funding, with total REDD+ assistance of about USD 1.7 billion and results-based commitments of USD 4.1 billion cumulative since 2010. Total finance for forests is insufficient, and is dwarfed by private investments and public-sector subsidies in agriculture and other deforestation drivers.

Furthermore, even if the REDD+ mechanism were dramatically scaled up, carbon-based payments would still be insufficient to generate economically optimum forest protection. According to one recent estimate, carbon and climate regulation services make up only about 39 percent of the total ecosystem services value provided by a hectare of tropical forest. There is no major performance-based financing supporting the non-carbon public goods from forests. The TFFF is being proposed in the context of an international forest financing landscape that is fragmented and insufficent:

- Foreign assistance to promote the development benefits of forests is limited.

- Support for forests' global public goods is limited in scope to just carbon.

- $\quad$ Even for carbon services, forests are globally underfunded through REDD+ compared to the value of those services.

- Progress in "greening" the trade and investment in forest-risk commodities is slow.

This paper describes a proposed approach to measuring and rewarding performance for the TFFF, a multilateral wealth fund whose excess returns would be used as performance payments to reward reductions in deforestation. Extensive research and growing practical experience on forest monitoring in the context of REDD+ informs the proposal, steering it towards approaches that would maximize the political feasibility and environmental effectiveness of the TFFF. Performance assessment would be based on changes in natural forest biomass, using a common reference level formula for all countries that incorporates national historical loss rates and a glide path toward zero net forest loss.

\section{Overview: A Proposal for a Tropical Forest Finance Facility}

This section outlines a proposal to establish the TFFF. It describes its goals, source of funding, and governance structure. The third section of the paper presents a theoretical framework for the roles of different international forest finance mechanisms, and explains how the TFFF fits into the existing system of international forest finance. The fourth section 
of the paper is focused on details of a proposed performance measurement and allocation approach and potential formulas for implementing the approach.

\section{Goal of the TFFF}

The overarching goal of the TFFF will be to slow and reverse tropical deforestation. The theory of change is that the promise of results-based payments to governments will raise the domestic political priority of forest protection by giving it financial value. This is expected to catalyze a shift in economic development pathways away from deforestation-intensive practices.

In creating the multilateral wealth fund, the immediate operational objectives are to: (1) maximize the returns on the invested capital so as to generate significant funds that can be used as performance payments; and (2) ensure that payments to tropical forest countries are made in accordance with a performance measure that is credible, sustainable, objective, and comparable across countries with reference to an agreed global benchmark.

By setting up a SWF-like financing mechanism that is funded with non-ODA assets, investors will both dramatically amplify the incentive to protect forests and maximize the efficient use of public credit.

\section{The Global Offer}

The global offer itself would be put forth by a group of investors. These can be governments of donor countries, philanthropies, or private investors for whom reducing deforestation is a high priority. The global offer will clearly specify how performance is to be measured and how the annual returns on the invested funds are to be allocated to forest countries. See section III for a discussion of country eligibility.

\section{TFFF's Financing Strategy}

The TFFF proposal is for a group of sovereign sponsors-with the potential participation of private sponsors, as well — to establish a large investment fund that would generate financial rewards for tropical forest nations that succeed in maintaining or enhancing their forests. These rewards would be comprised of the investment returns on TFFF, net of payments to sponsors to cover the cost to them to finance their sponsorship or a return equivalent to that of sovereign debt in the currency in which they make their investment This "excess return" is the foundation of TFFF's value proposition. Figure 1, below, illustrates this value proposition, based on excess returns that could have been generated over a 20 -year horizon had it been established in 1995. Over extended periods, developed-country borrowing costs have been greatly exceeded by the returns on diversified portfolios of equity, debt and other investments. 
Figure 1. TFFF funding model

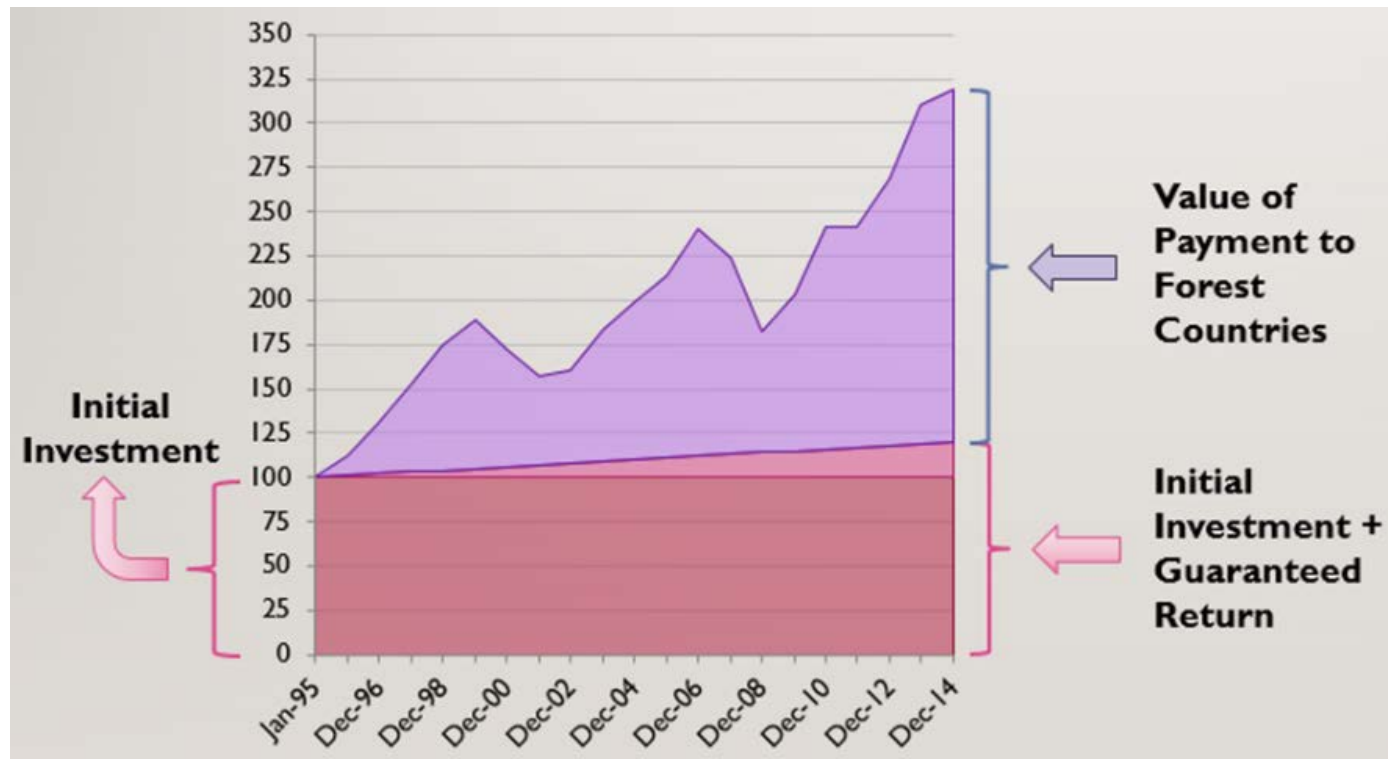

Investors would capitalize the fund with low-cost investments that, mostly, are uniquely available to sovereign governments. Their capital investments would be funded in a manner appropriate to their particular situation, whether from existing reserves, a sovereign wealth fund, government borrowing, or government-guaranteed bank deposits. Investors could expect the TFFF to repay their initial capital upon the maturity of the fund, and in the meantime, investors would receive interest payments commensurate with their cost of funds, e.g., high-grade government borrowing.

Capital contributions would not come from "official development assistance" or other government budgets. Rather, countries could draw on reserve funds, issue governments bonds, or draw on commercial savings deposits with government deposit insurance programs. If the TFFF were set up as a separate legal entity, it could conceivably borrow in global capital markets in its own name, with the benefit of sponsors' sovereign guarantees.

The TFFF will seek to generate returns greater than the cost of the capital by investing in a fully diversified portfolio of relatively riskier assets with higher expected returns, similar to the portfolios of major university endowments, foundations, sovereign wealth funds, and pension funds. To maximize capitalization and returns of the TFFF, it would be professionally managed consistent with best practice in the investment of comparable longterm funds or endowments.

The TFFF would operate for a fixed period (say, 20 years), after which the endowment would be liquidated and the original capital payment would be returned to the investors. The accumulated earnings would be distributed to tropical forest countries based on their accumulated shares, which would be based on performance.

As a starting proposal, it is suggested that the TFFF have as its target size USD 100 billion in capitalization. For the last decade (based on the average return to US university endowments and 
the average cost of short-term US government borrowing) a dollar-based fund would have returned on average about 5.5 percent, net of estimated expenses including the cost of borrowing. With such a return on its investments, the TFFF would grow over 20 years to about USD 300 billion net of interest cost and other expenses, resulting in USD 200 billion to be divided among tropical forest countries based on their performance in protecting their forest resources. For simplicity we outline a financial model that retains all returns until the end of the fund in 20 years. But it is possible to consider a model in which a portion of the returns is disbursed to performing forest countries in regular intervals (for instance every five years) or each year and any remainder at the end of the life of the fund. Investment returns should be awarded in a way that maximizes their incentive function, while minimizing the financial risk to investors.

For more information on the financial aspects of the proposal, see the companion CGD policy paper, "Creating a Multilateral Wealth Fund for a Global Public Good: Proposed Financing Strategy for a Tropical Forest Finance Facility."

\section{Governance Arrangements for the TFFF}

The governance arrangements for the TFFF would draw on principles and lessons from CGD's COD aid model and the Santiago Generally Accepted Principles and Practices of Sovereign Wealth Funds. The rules and formulas for measuring performance and allocating investment returns to forest countries would be agreed in advance of the TFFF's establishment and clearly defined in the global offer. The global offer would constitute a contract, with independent verification, between investors and tropical forest countries. It is neither a demand nor a requirement. To ensure confidence and trust in the arrangements by both investors and tropical forest countries, the offer should be transparent, credible, and insulated from political revisions. See the CGD policy paper "Creating a Multilateral Wealth Fund for a Global Public Good: Proposed Governance Arrangements for a Tropical Forest Finance Facility" for details.

\section{International Forest Finance and the TFFF}

Forests provide a range of ecosystem services that benefit people. ${ }^{3}$ But not all forests are equivalent in the types or amounts of ecosystem services they provide, the people that benefit from the services, nor in the extent to which those services are undervalued. The concept of ecosystem services focuses attention on the myriad ways forest land can meet human needs, makes explicit that forest conservation involves trade-offs between different people or needs, and provides a relative framweork for quantifying the costs and benefits of different forest land uses. ${ }^{4}$

\footnotetext{
${ }^{3}$ See, e.g., Millennium Ecosystem Assessment (2005).

${ }^{4}$ Mullan, K. (2014).
} 
The role and design of an international forest finance mechanism such as the TFFF, which seeks to increase the amount or value of ecosystem services that forests provide to people both locally and globally, can be usefully explored using three key dimensions of variation.

The first source of variation is in the biophysical and ecological properties of the forest land itself. A hardwood forest provides greater timber value than a pine or eucalyptus forest. A tropical forest houses greater species diversity than a temperate forest. A moist, dense forest provides greater carbon storage and climate protection value than a dry, open forest. A forest that is home to indigenous communities will provide greater cultural services than an unoccupied reserve. A healthy forest provides greater levels of most services than a degraded forest.

The ecosystem services value of a forest doesn't just depend on its biophysical properties, but also on the location of potential beneficiaries relative to the forest land. Those occupying forest land or with direct access to that land are the most likely to derive benefit from the provisioning of food, fuel, or timber. A farmer may derive value from the pollination services of a nearby forest without ever stepping foot in it. Water quality and rainfall regulation services would benefit everyone living or farming in the same watershed as a forest or everyone accessing electricity from a downstream dam. In contrast, someone halfway around the world will benefit from a forest mostly through the global public goods it provides, such as biodiversity preservation and climate protection.

Finally, different forest types and ecosystem services are more or less undervalued in formal economies, thus impacting how much intervention may be needed to incentivize rational land use decisions. For example, the provisioning services a standing forest—generating food, fuel, and timber-will more directly impact land use decision-making than regulating services like soil protection, water cycling, or climate regulation because they can be more easily monitized. And a much greater proportion of the total value of a diverse tropical forest takes the form of externalities (values or harms that impact people with no direct decision-making over its land use) than that of a monoculture timber or palm oil plantation, which generates most of its value through provisioning services that directly enter the formal economy.

These three dimensions of variation in ecosystem services - in the actual services provided by a particular forest, in the spatial relationship between a forest and potential beneficiaries, and in the extent to which a forests' ecosystem services are undervalued in the formal economy - provide context for understanding global efforts to finance forest conservation.

Mapping different forest ecosystem service values or forest types onto two of these key dimensions (Figure 2) can help identify the market failures that lead to undervaluation of forests. It also provides insights into the role of different types of international forest finance in reducing these failures. 
Figure 2. Mapping forest ecosystem services values

\begin{tabular}{|c|c|c|c|}
\hline \multirow{4}{*}{$\begin{array}{l}\text { Ecosystem } \\
\text { service } \\
\text { value is... }\end{array}$} & & \multicolumn{2}{|c|}{$\begin{array}{l}\text { The value of forest ecosystem service } \\
\text { is enjoyed primarily... }\end{array}$} \\
\hline & & $\begin{array}{l}\text { within the } \\
\text { forest country }\end{array}$ & $\begin{array}{l}\text { outside the } \\
\text { forest country }\end{array}$ \\
\hline & $\begin{array}{l}\text { more } \\
\text { marketable } \\
\text { (products) }\end{array}$ & $\begin{array}{l}\text { Quadrant } 1 \\
\text { Commodity } \\
\text { production for } \\
\text { domestic use }\end{array}$ & $\begin{array}{c}\text { Quadrant } 2 \\
\text { Commodity } \\
\text { production for } \\
\text { international } \\
\text { trade }\end{array}$ \\
\hline & $\begin{array}{l}\text { more } \\
\text { externality } \\
\text { (services) }\end{array}$ & $\begin{array}{l}\text { Quadrant } 3 \\
\text { Local regulation } \\
\text { and cultural } \\
\text { services }\end{array}$ & $\begin{array}{l}\text { Quadrant } 4 \\
\text { Global } \\
\text { regulation and } \\
\text { cultural services }\end{array}$ \\
\hline
\end{tabular}

The ecosystem service value forests provide as a source of timber would fall primarily within Quadrant 1: timber can be converted into revenue relatively easily by individuals living on or with access to the land. The ecosystem service value of forest land after conversion to agricultural production would also primarily fall within Quadrant 1: those controlling the land are directly generating economic flows through its use. Governments may transfer some of these more marketable ecosystem service values from the individual occupying or using the land to other citizens through fees or taxes that are used to enhance collective welfare, but much of the value remains within the forest country regardless. A rational and functioning government will seek to manage forest land to generate significant returns in Quadrant 1. In this quadrant, market failures such as corruption or insufficient infrastructure and access to credit will be primary reasons for land use decisions that are economically suboptimal in terms of forest cover.

International trade and investment can extend the economic value of marketable ecosystem services beyond the borders of the forest country (Quadrant 2). A consumer in China may benefit from the trade of soybeans produced in Brazil on former forest land through lower food prices, while an investor in London may extract some of the land rent by financing the sawmill that processed trees harvested to clear forests for the soy field. In both cases, the economic value of forest provisioning services are flowing beyond the borders of the forest country through economic transactions. Failures that lead to suboptimal ecosystem service provisioning in this quadrant would be based on the economics of international investment and trade and may include illegal logging, wildlife trade or forest clearing to provide highvalue products, or insufficient infrastructure for bringing products to international markets.

Much of the value of forest ecosystems is difficult to monetize, and would thus fall into Quadrants 3 and 4. Services like soil protection, water purification and flow regulation, and pollination benefit the people living near or downstream from forests, most likely within the 
forest country itself (Quadrant 3). Climate regulation of a forest benefits everyone in the world, with most of the benefit accruing outside the forest country (Quadrant 4). In these quadrants, the difficulty of "internalizing" externalities is the primary market failure.

The following sections use this framework to explore the current landscape of international financial flows that do or could support forest conservation; the potential roles of the TFFF to fill gaps in this landscape; and considerations about how to best measure progress and allocate resources for the TFFF depending on its role in international forest finance.

\section{The Current Landscape of Forest Finance}

Forest country governments and international donors have a range of different motivations, capacities and approaches for supporting the maintenance of forest ecosystem services. The framework developed above illuminates some of these differences, and how they are manifested in a variety of approaches to international forest finance-most notably aid, trade, investment, and climate finance (Figure 3).

\section{Figure 3. International forest finance modalities}

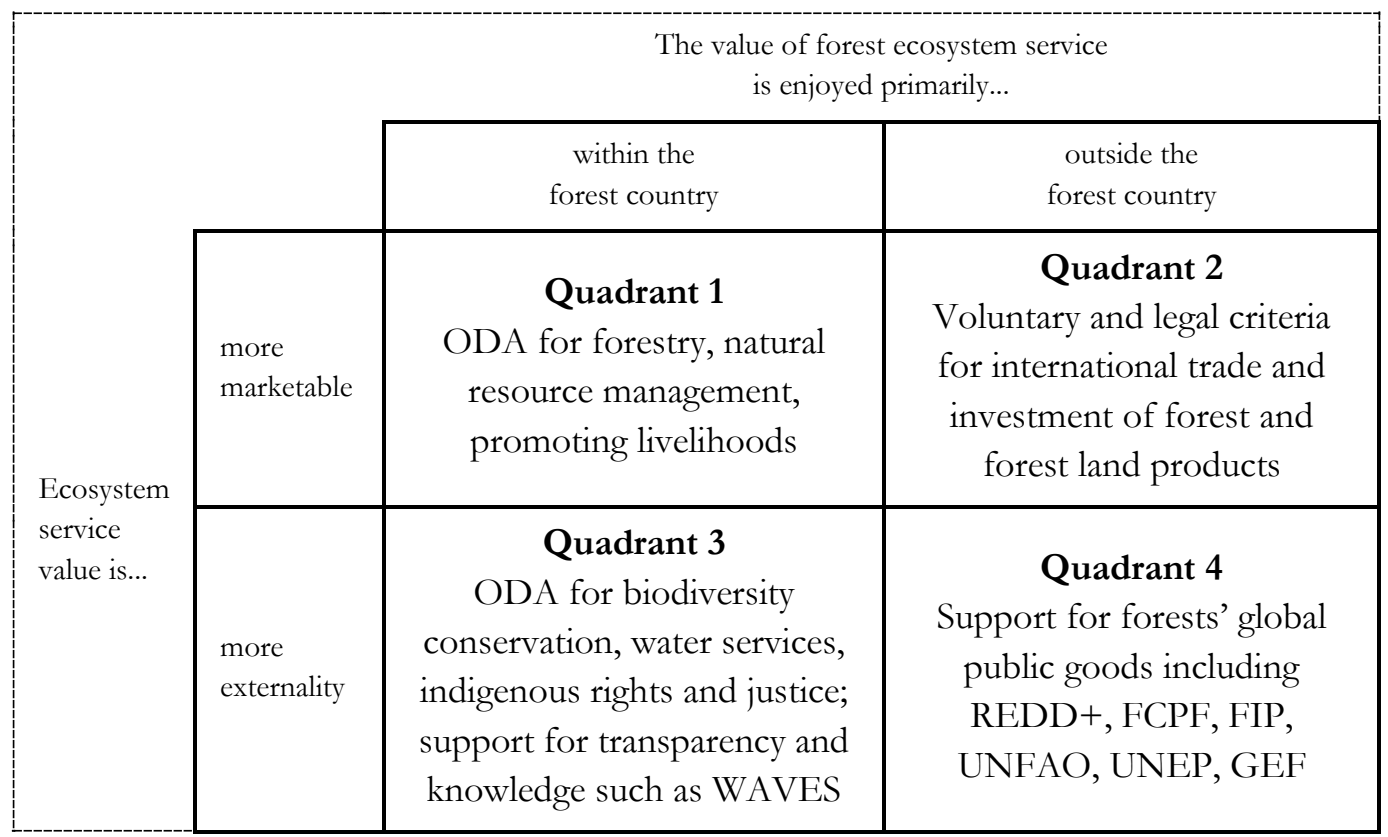

Support for forestry and forest management as an economic development tool was the traditional mode of forest-related official development assistance (ODA) through the 1980s or 1990s, and remains a priority for some international donors. This type of international support, primarily falling into Quadrant 1, has sought to increase the ability of forests and/or forest land to drive economic development and improve livelihoods. ODA programs in this quadrant have typically required significant safeguards to avoid exploitation of forest resources to generate marketable products while reducing their less-monetizable values. 
Over the past three or four decades, the center of gravity for forest-related ODA has shifted from Quadrant 1-with the primary objective being to maximize economic output- to Quadrant 3, where the emphasis has been on generating some economic benefits while maintaining and enhancing the ability of forests to provide a broader range of ecosystem services. ${ }^{5}$ These include programs to promote forest conservation and biodiversity, including through protected areas; programs to protect watersheds; and programs to advance the rights of indigenous communities to control their traditional and customary lands.

While the economic benefits of actions in Quadrant 3 may be less direct and more diffusemediated through ecosystem services that don't directly generate cash income- they are no less real. In fact, significant effort is being invested in estimating the economic benefits of forests and other natural ecosystems and ensuring that these values are appropriately mainstreamed into development planning and national economic accounts. ${ }^{6}$ Efforts such as these will increase the ability for governments to more effectively manage Quadrant 3 ecosystem service values.

Of course, the same forest area may provide ecosystem services that are both marketable and not. As such, there is no hard line between Quadrants 1 and 3. For example, programs such as those to promote ecotourism and agroforestry fall between the two-seeking to generate income by monetizing the usually externalized services from biodiversity (ecotourism), and by generating both income and non-income generating services by introducing trees into agricultural landscapes (agroforestry). Substantial effort has been invested in development approaches such as payments for ecosystem services (PES) that seek to shift ecosystem service values from Quadrant 3, where they are maintained primarily by regulation and legal enforcement, into Quadrant 1, where they can generate income for land-holders. Regardless, the distinction is helpful in understanding the primary underlying goal of forest programs: seeking first and foremost to generate income for landholders through monetization of ecosystem services, and for the broader citizenry through taxes or fees on economic activity; or seeking to generate greater welfare for both landholders and citizens through the maintanance of the full suite of ecosystem services.

Two mechanisms allow the direct economic benefits of forest ecosystem services to flow internationally: trade and foreign direct investment (Quadrant 2). Trade allows consumers to enjoy the economic value of substiting lower-priced imports for domestic production, and allows companies to generate profits through the flow of international products. Even when products are traded internationally, some of the economic value likely remains within the producer country. International actors may also derive economic returns from forest ecosystem services through investment-purchasing forest land outright or providing the capital to improve production or marketability of forest products.

\footnotetext{
${ }^{5}$ See, e.g., Wolosin (2012) and Collaborative Partnership for Forests (2012).

${ }^{6}$ For example the Natural Capital Coalition (https://naturalcapitalcoalition.org/), the Natural Capital Project (https://www.naturalcapitalproject.org/) and the Wealth Accounting and the Valuation of Ecosystem Services (WAVES) partnership https://www.wavespartnership.org).
} 
A substantial amount of effort has gone into "greening" international trade and investment flows related to forests and the marketable commodities that forests and forest land generate (e.g., timber, pulp, soy, palm oil). Such efforts seek to leverage the scale of these flows by focusing on the values of international consumers, consumer governments, and corporate traders to steer production in ways that protect rather than undermine forest externalities. However, recent analyses have shown that the amount of "green" trade and investment in sustainable commodities is dwarfed by the scale "grey" finance for the land sector that influences forests and is not clearly aligned with forest protection goals. ${ }^{7}$ And while voluntary corporate zero-deforestation commitments are spreading in forest-risk industries, ${ }^{8}$ their implementation lags and the proportion of companies with such commitments remains too low. ${ }^{9}$

Even in a world without development assistance, rational self-interest should drive distant countries to support forest protection in tropical countries to maximize their forests' provisioning of global public goods such as biodiversity and climate protection. However, international support for development-related global public goods such as climate mitigation and forest protection have been dramatically underfunded in recent years, equivalent to only about 10 percent of global spending on ODA. ${ }^{10}$

The REDD +11 track of negotiations under the United Nations Framework Convention on Climate Change (UNFCCC) has been working for more than a decade to build a global system to generate international finance for the climate regulation services that developing country forests provide. The most fundamental disagreement in the REDD+ negotiations has been centered on the commodification of the internationally-flowing ecosystem service value forests provide through carbon sequestration and storage. There remain divisions between parties on whether results-based REDD+ finance (so-called "Phase 3" REDD+) is predominantly a market mechanism that increases the value of forests through international trade and investment in carbon, internalizing the climate services of forests into the formal economy (e.g., Quadrant 2), or whether REDD+ payments to forested developing countries are primarily compensation for the climate protection value forests provide to the rest of the world (e.g., Quadrant 1). A third framing, especially relevant in the context of the Paris Agreement and Nationally Determined Contributions (NDCs), is that REDD+ is a framework that supports forest countries to pursue and account for their fair share of the needed collective action on global climate control. In this case, ambitious REDD+ action by forest countries generates climate protection services for their domestic benefit (Quadrant 3), in part through other Parties' more ambitious domestic climate actions in the context of enhanced collective ambition including REDD+ contributions by forest countries.

\footnotetext{
${ }^{7}$ Climate Focus (2017).

${ }^{8}$ Donofrio et al. (2017).

${ }^{9}$ Climate Focus (2016).

${ }^{10}$ Birdsall and Diofasi (2015).

${ }^{11}$ Reducing Emissions from Deforestation and forest Degradation and the role of conservation, sustainable management of forests and enhancement of forest carbon stocks in developing countries.
} 
There is less debate about the role of non-results-based REDD+ finance (so-called Phase 1 and 2 REDD+, representing readiness and implementation of policies and measures). Nearly 60 percent of an estimate of programmed REDD+ finance from 2006-2014 was for these earlier phases of REDD+, and virtually all this early-phase REDD+ has been through ODA. ${ }^{12}$ This type of REDD+ finance is predominantly Quadrant 1 and/or Quadrant 3intended to support forested developing countries' own economic well-being. In total, ODA commitments for REDD+ readiness and implementation has totalled about $\$ 1.7$ billion since 2010. ${ }^{13}$ This compares to at most $\$ 1.4$ billion of international forest carbon market transactions (Quadrant 2) since tracking began in the early 2000s, ${ }^{14}$ and up to $\$ 4.1$ billion results-based REDD+ commitments (Quadrant 4) since 2010, most of which has not yet been disbursed. ${ }^{15}$

Regardless of the modality and underlying theory of change, the scale of REDD+ support to date has been vastly insufficient compared to the need. Less than 2 percent of public international mitigation-related development funding supports forests, even though forests have the potential to provide up to 30 percent of the mitigation needed to meet global climate objectives. ${ }^{16}$

New sources of REDD+ finance may emerge; for example, the Green Climate Fund decided in October 2017 to pilot results-based finance for REDD+, setting aside up to $\$ 500$ million of its dedicated $\$ 991$ million REDD+ "window." ${ }^{17}$ However, this GCF REDD+ allocation is itself less than 10 percent of the total $\$ 10.3$ billion in pledges to the GCF during its initial resource mobilization period through June 2017, ${ }^{18}$ and it does not appear that GCF pledges have significantly increased public international finance flows from donor governments ${ }^{19}$-belying an argument that the GCF will fill the REDD+ finance gap.

There is a fragmented landscape of international financing to support the non-carbon global ecosystem service benefits of forests like biodiversity. There is some support for international forest knowledge and data public goods such as the Global Forest Resources Assessments of the FAO, and additional value provided through international cooperation and coordination of ODA resources flowing through the GEF and UNEP. Existing projectbased and capacity-building finance streams are insufficient, ${ }^{20}$ and there is no major peformance-based finance supporting the non-carbon global public goods from forests.

\footnotetext{
12 Norman and Nakhooda (2015).

13 ClimateFocus, 2017.

${ }^{14}$ Hamrick and Gallant (2017). Calculated as the amount of market finance from Table 1, excluding domestic purchases by the Australian Emissions Reduction Fund. About $\$ 116$ million in 2016. These total estimates are ceilings, as they include some domestic forest carbon market transactions in California, New Zealand, and elsewhere.

15 ClimateFocus (2017); Hamrick and Gallant (2017).

${ }^{16}$ ClimateFocus (2017).

17 GCF/B.18/23.

$18 \mathrm{GCF} / \mathrm{B} .17 / 02$.

${ }^{19}$ Buchner et al. (2017).

${ }^{20}$ Collaborative Partnership for Forests (2012).
} 
In short, the TFFF is being proposed in the context of an international forest financing landscape that is fragmented and insufficent:

- Foreign assistance to promote the development benefits of forests is limited.

- Support for forests' global public goods is limited in scope to just carbon.

- Even for carbon services, forests are globally underfunded through REDD+ compared to the value of those services.

- Progress in "greening" the trade and investment in forest-risk commodities is slow.

\section{Potential Roles for the TFFF}

The TFFF is at heart an attempt to generate significant new finance to generate pay-forperformance incentives for tropical forest conservation. As outlined in Section II above, the TFFF proposal includes two key innovations: 1) the way it will raise funds, by converting low-cost sovereign credit from mission-driven investor countries into cash that can be used to drive change in developing countries, through an instrument similar to a Sovereign Wealth Fund; and 2) the way it will distribute funds, using the Cash-On-Delivery-Aid approach that supports country-ownership and only pays for results as they are achieved and verified.

As the TFFF moves from conception to actualization, these two key innovations will continue to be the engine that drives investor interest. However, they are not sufficient on their own to define the facility. Further strategic narrowing is necessary, in particular with respect to how the TFFF will fit into the existing global landscape of tropical forest finance. Existing strategies to slow and reverse tropical deforestation—such as REDD+, conservation ODA, supply chain initiatives, and rights-based approaches-have generated substantial investments of time, political capital, and development and climate finance from some of the same policy makers who will be approached to support the TFFF. The TFFF will only be successful if it complements these existing strategies.

The following sections assess options for the TFFF's potential role in the international forest finance landscape. Three narrow options are assessed briefly, while a fourth and broader approach is recommended that encompasses elements of the previous three.

\section{A Results-Based Development Finance Facility for Forest Ecosystem Services}

One option for the TFFF would be to focus primarily on development objectives-seeking to reward tropical countries for increasing the forest ecosystem service values that improve well-being domestically (Quadrant 3 and potentially also Quadrant 1). Payments would be designed to encourage national land use decision-making that is optimum for each country's specific development pathway, independent of any other country's benefits. Benefits to investors would be indirect, similar to the benefits of all ODA, mediated primarily through increased wealth, economic activity, well-being, and stability in forested developing countries. 
This model of the TFFF's role and objectives would have several implications for the development and design of the TFFF, in particular with respect to country selection, performance assessment and rewards allocation:

- The TFFF might select participating countries based development status. For example, the TFFF could include only low-income forested least developed countries and exclude middle-income countries. For lower-income countries, the scale of TFFF payments could be much more significant compared to existing government revenues than in middle-income countries.

- The performance assessment and rewards allocation functions might take into account development status, perhaps based on perceived capacity to self-financing and/or implement development initiatives. For example, the TFFF could allocate a higher proportion of fund resources to lower income as opposed to middle-income countries, or the equations for assessing performance benchmarks could include development status (e.g., recognizing that a poorer country may have less capacity to implement improved forest land management or have greater need to convert forests to agriculture to meet food security objectives).

- There might be less demand for payment equity across different forest countries even within income categories, suggesting that maximum reward payments could account for the specific role and extent of forest ecosystem services in a country's planned development pathway. For example, a country with extensive hydroelectric power capacity might receive greater payments, as the development value of upstream forest protection might be greater.

- A facility focused on domestic forest-country development benefits (and not global climate regulation services) might be perceived differently vis-à-vis complementarity between the TFFF and REDD+. For example, investors may not be concerned with overlap or "double paying" between a robust pay-for-performance (phase 3) REDD+ system providing payments in proportion to the global climate regulation value of a country's forests and the TFFF providing payments in proportion to the domestic development benefits of the same forests.

- With a primary focus on domestic economic development, the TFFF could seek to incentivize both ecosystem service values that are directly marketable (Quadrant 1) as well as those that are externalities (Quadrant 3). If so, the monitoring and performance assessment approach might include both natural and plantation forests within the scope of the TFFF. A natural-forest only approach would also be consistent with a primary focus on forest country development.

- A decistion to prioritize domestic ecosystem service benefits rather than global public goods may suggest using a forest area-based performance measurement rather than a forest biomass-based approach, if forest area correlates more closely with provisioning of local and regional ecosystem services. 
- A decision to focus on forest-country development benefits rather than global public goods might make it more difficult to attract investor interest to the TFFF, for example due to the global political prioritization of climate mitigation and given the facility might never get up and running, if most potential donor interest is driven by climate concerns.

\section{A Forest Carbon Facility}

A common question raised during the development of the TFFF concept has been: "isn't this just a phase 3 REDD+ instrument?" It would be, if the strategic role of the TFFF were to provide payments exclusively for the carbon-based climate benefits of tropical forests. The two key innovations mentioned above - a new way to raise funds, and distributing funds using a Cash-on-Delivery approach — could be applied in the carbon/climate context if the TFFF were designed and positioned as a REDD+ instrument.

This approach would have a wide range of implications for the development of the TFFF, as such an instrument would need to fit within the internationally-agreed guidelines for REDD+, including the key elements of the Warsaw Framework for REDD+ agreed at COP19 in November 2013 (the so-called REDD+ Rulebook). ${ }^{21}$ While a full assessment of alignment between a carbon/climate focused TFFF and the Warsaw Framework for REDD + is beyond the scope of this paper, three related requirements for developing countries to access results-based payments are especially relevant in considering performance assessment:

- Forest countries must ensure that forest-related carbon emissions and removals resulting from implementation of REDD+ activities are fully measured, reported and verified in accordance with UNFCCC guidance;

- Forest countries must have in place a robust and transparent national forest monitoring system; and

- Forest countries must have in place a national forest reference emission level and/or forest reference level, which are to serve as benchmarks for assessing REDD+ performance and are established by voluntary submission of proposals to the UNFCCC.

Together, these requirements take an activity-based approach and assign responsibility for setting benchmarks and measuring performance under REDD+ to forest countries, using national forest monitoring systems. However, three structural features of the TFFF proposal suggest the need for a consistent approach to monitoring and assessing performance that is comparable across all tropical countries eligible for payments, and independent from any individual forest country's data: the "global offer" approach, the "zero-sum" division of

${ }^{21}$ See, e.g., Climate Law \& Policy (2015). 
fund proceeds, and the need to minimize overhead and organizational complexity in the administration of the TFFF.

One of the key features of a cash-on-delivery approach like the TFFF is the need for independent verification of results. ${ }^{22}$ The TFFF design seeks to maximize its global incentive value, planning to disburse all of the facility's excess returns to high performers. This implies that one forest country's success will reduce the payment to every other successful forest country in a zero-sum fashion. For both of these reasons, if forest country national statistics were used as the primary performance-monitoring basis, independent verification using satellite-based data would be required regardless, along with a process for reconciling observed differences and entertaining grievances. Such a process would add a significant amount of overhead and organizational complexity to the TFFF's operations.

Another issue with a carbon/climate focused TFFF is that it may raise concerns among investors that they are supporting the same emission reductions twice-once through the TFFF, and again through other REDD+ instruments. This concern would be especially relevant for countries interested in selling or buying forest carbon credits to meet compliance obligations under domestic climate regulations or to meet Paris NDCs. The TFFF would likely need to address these "double-counting" issues by aligning performance assessment and emission reduction registries with other REDD+ instruments (such as the FCPF Carbon Fund, the Green Climate Fund's pay-for-performance REDD+ facility, and/or market systems such as ICAO's CORSIA).

There may be benefits to designing the TFFF as a phase 3 REDD+ instrument, as well as drawbacks. For example, one of the primary weaknesses of REDD+ to date has been a lack of certainty that phase 3 funding would be available to forest countries at the scale needed. An endowment-like structure for generating funds, such as proposed for the TFFF, could provide a previously unavailable level of certainty that significant funds will be available for successful forest protection over a 20 -year time horizon. If large enough, such a facility could even have some benefits over a market-based mechanism, as forest emissions reductions would not be used to offset emissions elsewhere.

\section{A Non-Carbon Global Public Goods Facility}

A third option would be for the TFFF to provide payments to forest countries for the noncarbon ecosystem services that their forests provide to the rest of the world. These would include the global public good values of biodiversity, water and nutrient cycling, and noncarbon climate services such as albedo and aerosol forcings. This approach to the TFFF would be a pure "global public goods" mechanism that would avoid any potential overlap with REDD+ (although it would have some overlap with the mission of the GEF Biodiversity Fund). Conceptually, forest countries would "pay for" forest ecosystem services that generate domestic economic benefits through management decisions that forego alternative land uses, up to a domestic optimum (and potentially with the support of ODA);

22 Birdsall et al. (2012). 
a REDD+ mechanims would pay for global public good value of forest carbon sequestration and storage services; and a non-carbon TFFF would pay for the remaining global public goods value of tropical forests.

This approach would have a number of design implications for the TFFF:

- The performance assessment and rewards allocation functions would not include any adjustments to account for the development status of forest countries.

- Investor countries would not be able to account for their TFFF contributions as either ODA or climate finance.

- The performance assessment functions would ideally correlate closely with noncarbon and non-local ecosystem services provisioning, potentially including estimates of forest biodiversity.

- This design may not be of interest to potential investors with a strong focus on the climate protection and development benefits of tropical forests- the two dominant narratives in the current landscape of international forest finance.

\section{Recommended Approach: A Tropical Forest Public Goods Facility}

Each of the above sections presents an option for a narrow strategic role of the TFFF within the landscape of international forest finance. After more than two years of stakeholder consultations and development of the TFFF concept, a broader role for the TFFF has emerged as the most viable option: a facility to support the full range of less-marketable tropical forest ecosystem services. This conception of the TFFF would seek to incentivize tropical forest protection and expansion for three objectives:

1. Forest country economic development through greater provisioning of local and regional (domestic) ecosystem services (Quadrant 3); and

Greater provisioning of tropical forests' international and global public goods (Quadrant 4), including:

2. Non-carbon international and global public goods services, including biodiversity, water and nutrient cycling, and non-carbon climate services; and

3. Climate protection services through carbon storage and sequestration.

This approach would invite participation from the broadest range of potential investors, increasing the ability of the TFFF to generate investments at the target scale. Sovereign investors face varying domestic contexts, and may be more able to generate the political will and legal authority to participate in the TFFF if they can point to any one or all three of the above objectives. Investors may also have broader flexibility in how they account for their TFFF investments in the context of international forest finance. For example, some investor countries may consider the "excess returns" from the TFFF that are used for performancebased payments as meeting climate finance commitments, as support for non-climate global public goods, and/or as ODA (after consultation with the OECD-DAC). 
A broad approach would also support the full participation of middle-income countries, which are home to some of the largest and most threatened tropical forests in the world. Upper-middle income/IBRD countries such as Brazil, Colombia, Peru, Mexico, Malaysia, and Gabon are home to more than 40 percent of the world's tropical forests and about 45 percent of tropical tree cover loss. ${ }^{23}$

A strategic focus by the TFFF on correcting the market failures leading to underinvestment in tropical forests' public goods would support an emphasis of natural forests over plantation forests. Excluding plantation forests from the TFFF—or at a minimum industrialscale plantations - is becoming technically feasible, would be attractive to many potential donors, and would avoid the perverse incentive that would result from reducing the cost of converting natural forests to plantations. A plantation exclusion would also reduce the ability of the TFFF to incentivize reforestation, much of which is likely to be in the form of plantation timber or tree crops. Technical solutions might be possible, for example by including plantations below a threshold size or by including new plantations within the scope of the TFFF as long as they are not substituting for natural forest loss.

Including carbon-based global climate services explicitly within the scope of the TFFF's objectives would require a clear understanding of the relationship between the TFFF and REDD+, as there would be some overlap in objectives. We believe that the opportunities from such overlap far outweigh potential risks, and that the risks can be managed sufficiently. The benefits and complementarities would include:

- Greater certainty of future payments. We believe that an additional source of pay-forperformance funding for tropical forests would "supercharge" REDD+ by providing a level of certainty about future payments that has, to date, been lacking. This certainty would drive tropical forest country policymakers to invest additional time, political capital, and resources towards implementation of REDD+ strategies.

- Complementarity of payment and monitoring timelines. Most REDD+ finance that has been made available is near- to mid-term finance. There is very little clarity about sources of REDD+ finance past 2030. The bulk of TFFF rewards would come towards the end of an expected 20-year time horizon, with monitoring extending at least through 2040.

- Complementary financing modes. Countries that lack capacity for delivering forest protections would have a greater incentive to build that capacity, including by seeking out and effectively utilizing technical assistance and funding that has been made available through Phase 1 and Phase 2 REDD+ instruments.

- Complementary theories of change. The TFFF would provide direct payments to central governments in the form of foreign exchange revenue, which would create an

\footnotetext{
${ }^{23}$ Estimates from Hansen et al. (2013) based on 2000 tree cover and 2000-2014 tree cover loss at 20 percent cover threshold, and World Bank country groups. World Bank Country and Lending Groups. datahelpdesk.worldbank.org/knowledgebase/articles/906519-world-bank-country-and-lending-groups
} 
incentive for forest country finance ministries to share responsibility for forest conservation objectives with enviroment and climate ministries, which have been the focus of REDD+ instruments. TFFF payments to central governments may support the removal of agricultural subsidies or other perverse incentives for forest clearing, while the benefits-sharing approach of REDD+ payments supports rural communities more directly.

Perceived risks of strategic overlap with REDD+ include:

- Investors might be concerned that the TFFF would be "double paying" for emissions reductions alongside REDD+ payments. This should be a minor concern, given the full value of tropical forest ecosystem services far exceeds the scale of REDD+ payments.

- Investors and forest countries alike may be concerned about duplicative instruments and proliferating criteria for defining deforestation reduction success, for example with the FCPF Carbon Fund or a REDD+ results-based "window" that might emerge from the Green Climate Fund's pilot program.

- Forest country participants or investor countries might push to apply some or all of the REDD+ processes and requirements to the TFFF, essentially "weighing down" the TFFF's implementation, increasing administrative costs and reducing the funds available for payments.

- Forest country participants might push for the TFFF to follow REDD+ guidelines in the use of nationally determined baselines and country-owned data for performance assessment. Such an approach would risk investor confidence and the ability to stand up the TFFF with sufficient investments. It would also reduce the ability to assess performance and allocate payments with minimal investments of time and resources, and would reduce equity across different forest countries.

These risks of strategic overlap with REDD+ can be mitigated in several ways, including:

- Maintaining the emphasis on the TFFF as a broad tropical forest public goods facility, not limited to just carbon. This will maintain the TFFF as a distinct mechanism from REDD+, although highly complementary.

- Financing the operation of the TFFF out of the excess returns, such that any tendency by donors or forest countries to "weigh down" implementation would reduce the availability of funds for payments. Clearly and consistently communicating this trade-off during the development of the TFFF would provide incentive to both investors and forest countries for maintaining simplicity.

- If "double paying" remains a major concern for some investor sponsors, the risks for these sponsors could be avoided if their funds were segregated and used to generate payments that do not exceed the domestic development benefits and non- 
carbon global public goods from tropical forests, which could be estimated by natural capital assessment tools.

The next section of this working paper outlines an approach to measuring performance and allocating funds for the TFFF, following the recommended option of a tropical forest public goods facility encompassing both forest country development and global public goods objectives.

\section{Performance Assessment and Rewards Allocation}

The approach to performance assessment and rewards allocation should follow from the objectives and role of the TFFF within the landscape of international forest finance. At the most basic level, what you measure is what you value. In this sense, the performance measurement and rewards allocation approaches are the very heart of the TFFF proposal. They will also help determine - in part — whether the TFFF is able to generate sufficient investor interest and trust to move towards implementation. The performance assessment and allocation approaches together will also determine how successful the TFFF is in achieving its objective: reducing and reversing tropical forest loss.

Researchers have invested more than a decade of work on how to measure success in reducing and reversing forest loss through results-based payments in the context of REDD+. While the TFFF will have a broader set of objectives than REDD+, it is useful to build on existing REDD + frameworks for understanding the elements and implications of the TFFF proposal. A compendium of REDD+ proposals by NGOs and Parties to the UNFCCC, compiled to help negotiators understand their different approaches and elements, provides such a framework. ${ }^{24}$ Four building blocks are compared for each proposal: scope (which activities are eligible), reference level (how reductions are calculated), financing (where the money comes from), and distribution (where the money goes). An approach to monitoring is a fifth building block, ${ }^{25}$ which the TFFF seeks to achieve through global satellite data. Together, these elements determine a proposal's impacts, including its political feasibility, environmental effectiveness, economic efficiency, and equitable distribution. ${ }^{26}$ Certain elements of the TFFF proposal will drive the designs proposed for each specific building block.

\footnotetext{
24 Parker et al. (2009).

25 In an influential options assessment for REDD+, Meridian Institute (2009) focuses on four key areas: finance; reference levels; monitoring, reporting, and verification, which included a section on scope of activities; and promoting effective participation of indigenous peoples and local communities. Additional background for this section is also provided by the follow-up report, Meridian Institute (2011).

26 Parker et al. (2009). It is worth noting that the TFFF will allocate future but unknown proceeds among forest countries based on relative performance, rather than setting a price per unit of performance or using markets to capture reductions in order of cost or price. In this context, the environmental effectiveness and economic efficiency of the instrument will be very closely related.
} 


\section{High-level Design Drivers}

The financing approach for the TFFF is clearly defined: investors provide funding at low cost, e.g., competitive bond market rates through a range of potential mechanisms. The funding is invested in a diversified endowment-like portfolio. Excess returns over debt service and facility costs are the source of pay-for-performance rewards to forest country nations for protecting and expanding forests. There are implications of this financing approach for the performance assessment and rewards allocation approaches, which include:

- Investors will demand a high level of confidence in the performance assessment approach. Excess uncertainty or large errors in measurement could create financial liabilities for the TFFF, which investors will seek to avoid.

- The need to minimize overhead costs, to maximize the amount of funding available for payments. This would suggest, for example, using the same data sources and processing for all countries, potentially through partnerships with other forest monitoring efforts, and avoiding lengthy negotiations and costly appeals processes regarding baselines or input data.

- The need to distribute the bulk of payments at the end of the fund's life. Given market volatility, the chances that the fund is unable to pay back investor capital increases as annual withdrawals increase, even though this probability is vanishingly small in most scenarios. The expected total amount available for payments also decreases as annual withdrawals increase (see below).

Political feasibility will place additional demands on the TFFF's performance assessment and asset allocation approaches. The finance ministries holding the purse strings in potential investor countries will consult with climate, environment, and development ministriesincluding experts on forest monitoring and those heavily invested in existing REDD+ instruments - to ensure buy-in for the TFFF concept and design details. Investors will also want to avoid reputational risks from domestic stakeholders, such as environmental and human rights NGOs. This will have some predictable impacts on the performance assessment and asset allocation approaches, and is certain to also raise issues that will require negotiation by likely investors as the TFFF moves forward. These include:

- The need to align with interests of constituencies in investor countries, to help give the TFFF the best chance of raising funds. This would suggest, for example, excluding plantation forestry, which is problematic for some investors; and capturing reforestation and forest degradation to the extent possible, which are of great interest to many investors.

- The need to create buy-in among forest countries for performance measurement and allocation approaches. While the instrument is structured as a global offer, investor sovereigns will need the TFFF to be viewed by tropical forest countries as helpful and well-designed, supporting country systems and priorities. 
- The need to address concerns about alignment and/or overlap with REDD+ and existing ODA programs. In particular, the performance assessment and allocation proposal for the TFFF should address the benefits of using satellite monitoring rather than country-based national forest monitoring systems, and of setting baselines using a common formula for all countries rather than having countries propose their own baselines.

- The need to address social and environmental safeguards before payments are made, to avoid incentivizing damaging policies that are nevertheless successful at reducing forest loss (e.g., community displacement).

As proposed above, the TFFF will be focused on providing incentives for countries to maintain and expand the public goods provided by their tropical forests for domestic development purposes and to enhance global well-being. This suggests that the scope of the TFFF's performance assessment approach should:

- Focus on natural tropical forests, both dry and humid, but generally excluding industrial-scale plantation forests. Natural forests are where the biodiversity and other ecosystem services, carbon benefits, and social and cultural benefits are greatest, and where there is the greatest market failure requiring intervention. If technically feasible, agroforestry and small-scale plantations could be included in performance assessment to the extent that they provide non-market benefits.

- Utilize indicators closely correlated with ecosystem services. Monitoring would capture, to the extent possible, a wide range of forest transitions and forest health changes that impact ecosystem service provisioning: deforestation, forest degradation, reforestation and forest restoration.

The remainder of this section provides an outline of proposed options for monitoring data, for performance functions including reference levels, for allocation functions to determine distributions of rewards between countries, and for payout timing approaches (Figure 4). These proposed options are aligned with the above design drivers, and seek to maximize the environmental effectiveness, economic efficiency, and equity of the TFFF while balancing necessary tradeoffs. 
Figure 4. TFFF performance evaluation flow diagram

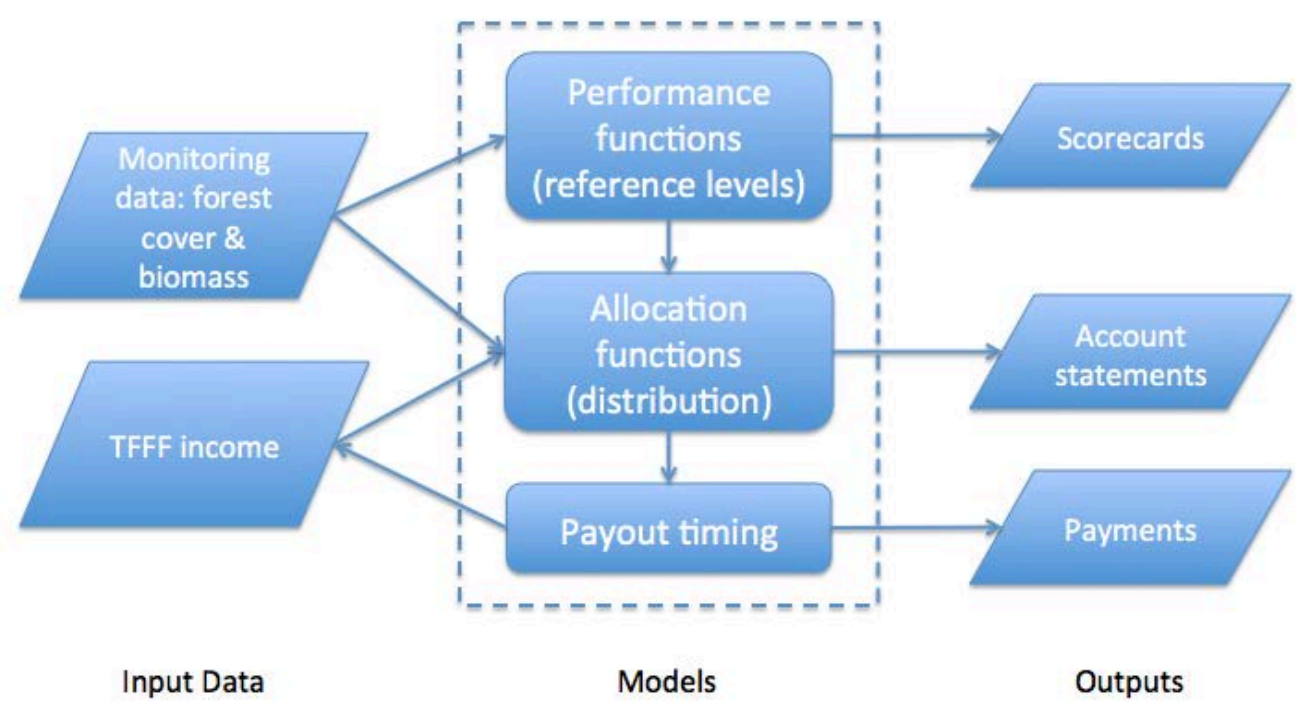

\section{Monitoring Data}

\section{Data Source}

One key tradeoff in the design of the TFFF is between measuring performance using global versus national approaches to monitoring deforestation rates. In the former, internationally consistent satellite data, generated using common definitions and algorithms, is used to assess and monitor forest loss for each country by a third party; in the latter, national definitions of forest and national inventories are combined with various satellite inputs to estimate forest cover change by the country itself. Table 1 outlines several advantages and disadvantages of these two options. 
Table 1. Satellite monitoring versus country systems

\begin{tabular}{|c|c|c|}
\hline & Advantages & Disadvantages \\
\hline $\begin{array}{l}\text { Global } \\
\text { approaches }\end{array}$ & $\begin{array}{l}\text { - Generates greater investor confidence } \\
\text { - Avoids moral hazard in country reporting } \\
\text { - Avoids negotiating data quality with each } \\
\text { forest country } \\
\text { - Avoids conflict between forest countries that } \\
\text { may arise due to the TFFF's zero-sum } \\
\text { distributions } \\
\text { - Is verifiable by third parties } \\
\text { - Can be designed to meet TFFF objectives } \\
\text { - May provide additional data and incentives } \\
\text { for alignment between national systems and } \\
\text { third-party observations } \\
\text { - Allows consistent approach to baselines } \\
\text { across all countries }\end{array}$ & $\begin{array}{l}\text { - May be less accurate or biased } \\
\text { in some locations compared to } \\
\text { country systems that account } \\
\text { for unique monitoring } \\
\text { challenges }\end{array}$ \\
\hline $\begin{array}{l}\text { National } \\
\text { approaches }\end{array}$ & $\begin{array}{l}\text { - Provide additional incentive to build } \\
\text { domestic monitoring capacity } \\
\text { - Account for domestic forest definitions and } \\
\text { align with country reporting in other } \\
\text { contexts, including REDD+ } \\
\text { - May reduce errors by matching monitoring } \\
\text { to forest types and properties (e.g., to } \\
\text { account for shifting cultivation, or scale of } \\
\text { disturbances) } \\
\text { - May reduce errors by including ground-based } \\
\text { sampling techniques }\end{array}$ & $\begin{array}{l}\text { - Subject to perverse incentives } \\
\text { - Viewed with skepticism by } \\
\text { some potential international } \\
\text { investors } \\
\text { - } \text { Review and external verification } \\
\text { would require additional } \\
\text { processes and overhead costs } \\
\text { - Would be nearly impossible to } \\
\text { assign consistent baselines to all } \\
\text { countries using country data }\end{array}$ \\
\hline
\end{tabular}

Recommendation: Emerging evidence shows that global approaches are sufficiently accurate to use for deforestation rate monitoring, and that the large differences observed between global data and national data for some countries can often be explained by aligning the spatial scope. ${ }^{27}$ We believe that the advantages of a global satellite monitoring approach in the design and implementation of the TFFF outweigh the disadvantages. It could be difficult to generate investor interest with a national monitoring tools. Therefore, we recommend that in the TFFF performance in maintaining and expanding natural forests be measured using global satellite data that is, to the greatest extent possible:

(a) comparable across all countries,

(b) accurate in measuring natural forest loss,

(c) consistent across time,

(d) complete by including all areas of natural forest without exclusions,

(e) transparent so that results can be reproduced and share allocations can be verified by investors, forest countries, and independent researchers, including being made publicly available to all if possible.

${ }^{27}$ Harris et al. (forthcoming). 


\section{Data Inputs}

It is not possible to directly measure the value of forest ecosystem services of a particular forest area from satellites. Pantropical time series are currently available that can map tree canopy cover from high resolution Landsat visual imagery ( 0.09 ha pixels), and aboveground biomass from medium resolution MODIS multispectral imagery (21.5 ha pixels). Tree canopy cover change and forest biomass change can be estimated from these products, and new products are in the research and production pipeline.

With these existing and expected future satellite-based forest products, the TFFF faces a choice: it could base performance on estimates of forest area, forest biomass and/or carbon $^{28}$, or a combination of all three. Forests provide many services (e.g., biodiversity and watershed protection) in addition to carbon storage that benefit local communities, states, regions and global populations. Ideally, the underlying measure of performance would be as closely related as possible to total ecosystem services rather than just climate services. There is a longer historical record of imagery that has been processed to estimate forest area, although new methodologies are being developed to use similar visual imagery to estimate biomass and new satellite products are being developed that measure biomass stocks and stock changes directly. The value of many ecosystem services provided by forests are more closely related to biomass density than to the mere presence or absence of tree cover above a threshold (e.g., forest area), especially over local and regional spatial scales..$^{29} \mathrm{~A}$ biomassbased performance measure for the TFFF would also be sensitive to forest degradation, rewarding countries for maintaining the health of their forests, while an area-based measure would focus solely on avoiding conversion of forest. Only carbon-based reference levels are allowed under the UNFCCC for REDD+, although some countries have used a simple calculation of area change multiplied by an average carbon density (or emissions factor) in their proposed reference levels.

In brief, an area-based performance measure would likely:

- Require fewer conversion factors and assumptions to translate satellite observations into assessed forest statistics, compared to carbon stocks and flows;

- Send a signal that carbon is not the only ecosystem service benefit provided by forests;

- Increase differentiation between the TFFF and existing REDD+ finance tools;

- Provide relatively greater benefit to countries with dry forests versus moist forests; and

\footnotetext{
${ }^{28}$ The ratio of biomass to carbon content is relatively consistent in forests around the world, at about 2:1, and estimates of observed aboveground biomass are commonly used to estimate carbon content. We focus in this paper on biomass, in recognition that carbon sequestration is only one of the ecosystem services forests provide. ${ }^{29}$ This is of course the case with carbon storage services, and there is significant evidence that biodiversity and ecosystem functioning are also related to biomass.
} 
- Provide equal benefit for maintenance of all natural forest area, regardless of forest health, thus providing as large an incentive to preserve degraded forest fronteirs as remote forest interiors.

A biomass-based performance measure would likely:

- Be more complex, although new datasets are being released that estimate biomass changes directly;

- Correlate better with ecosystem service benefits than area alone;

- Increase the similarity between the TFFF and existing REDD+ instruments, and the potential concerns of investors about double paying for deforestation reductions;

- Increase the ability of investors to recognize the foregone returns on TFFF investments as climate finance;

- Provide relatively greater benefit to countries with moist forests versus dry forests;

- Provide greater benefit for maintenance of healthy (less degraded) forests, providing an incentive for governments to direct any necessary forest loss to degraded areas with lower ecosystem service value.

Additional research is needed to investigate the correlations between satellite-based tree cover and forest biomass estimates and independent estimates of various ecosystem service values. We expect that changes in biomass will be the best correlate at local to national scales to changes in forest ecosystem services, and should be the core dataset for the TFFF's national performance evaluations. At the pantropical scale, we expect that some combination of forest biomass and tree cover area will be needed for an equitable distribution of awards between countries. The cost of obtaining wall-to-wall annual biomass estimates may be prohibitive, and could potentially be reduced by using tree cover maps for change detection and concentrated sampling.

Recommendation: We therefore recommend that the TFFF pursue using both forest biomass and tree cover area data as inputs. Ideally, the TFFF would obtain national-scale annual ${ }^{30}$ observations of natural forest area ${ }^{31}$ and biomass ${ }^{32}$ contained in natural forests using consistent satellite sources and data processing methods, either pantropically or for every country with significant tropical forest cover. ${ }^{33}$ The

\footnotetext{
30 We recognize that cloud cover and phenology differences between countries complicate annual estimates. If biomass data is significantly more expensive to obtain than area data, the biomass series (and its first difference) could be less frequent than annual.

${ }^{31}$ Generally speaking, by "natural" we mean non-plantation and non-agricultural forests with some age-class and biological diversity and structural complexity. A natural forest area estimate could be achieved with current technologies by applying polygon maps of plantation forests as a mask. By "forest area" we mean a tree-canopy cover definition of forest rather than a land-use definition, preferably at a low tree cover threshold in the range of 10-20 percent, in line with the definition of forest used by the FAO and in most countries.

32 Likely just above-ground live biomass (AGB) due to data limitations, although we recognize that other pools (e.g., below-ground biomass, coarse woody debris, etc.) vary significantly across different forest types and may be important indicators of ecosystem function and services.

${ }^{33}$ See section below on "Country participation" for discussion.
} 
net first difference series for both core data streams would also be calculated (annual net change in natural forest area and annual net change in natural forest biomass).

Natural forests are proposed to be the focus of the TFFF, as opposed to plantation forests, to be consistent with the proposed objectives of the facility as a forest public goods facility, and to ensure political feasibility of the instrument among investors who may be sensitive to providing an incentive for expanding plantation forests. Only a small proportion of the ecosystem services provided by natural forests is valued by markets, while most of the economic value of plantation forests is already monetized. The market failure associated with the provisioning of forest ecosystem services therefore impacts natural forest cover much more than plantation forest cover. The properties of natural forests of relevance for the TFFF include a predominance of native species, along with diversity in age and canopy structure and intact and functioning soils and root systems. These properties are not currently measured directly by satellites.

Net change is proposed to be the focus for performance measurement in the TFFF, as opposed to gross loss, in order to reward countries that both maintain and expand forests and to capture progress in avoided deforestation, avoided forest degradation, and reforestation. There are risks to applying a measure of net change-for example, net biomass can increase even in the face of deforestation if unmanaged lands gain more carbon than is lost. Additional research is needed to better understand how to combine both area and biomass together to assure that the TFFF avoids perverse incentives by using a net loss approach.

Both area- and biomass-based pantropical forest datasets are available with historical estimates stretching back more than a decade. The tree cover dataset by Hansen et al. included in WRI's Global Forest Watch (GFW) ${ }^{34}$ uses Landsat $30-\mathrm{m}$ visual imagery to generate maps of tree cover in 2000 and 2010 and annual estimates of gross tree cover loss from 2001-2016, both at a range of tree cover thresholds; and an estimate of gross tree cover gain from 2000-2012 at 50 percent cover threshold. More recently, Baccini et al. published a pantropical time-series of net annual changes in aboveground carbon density from 20032014 based on MODIS satellite data calibrated with field measurements and aerial LiDAR data. ${ }^{35}$

Neither of these currently available sources is ideal, however. The Hansen et al. series has a number of known issues, including a greater sensitivity to cover losses than gains, thus failing to provide an adequate estimate of net tree cover change. The Baccini et al. estimates

\footnotetext{
${ }^{34}$ Hansen et al. (2013). National data available through Global Forest Watch from: www.globalforestwatch.org

35 Baccini et al. (2017). It is important to note that the use of these two sources together (one providing area change, the other biomass) may be problematic, as many areas of biomass losses and gains in the Baccini map don't match well with areas of tree cover loss and gain in the Hansen map, and these differences are not yet well understood. Presumably these issues will get resolved over the next few years as Baccini et al. are currently testing their biomass model with Landsat rather than MODIS imagery. There are additional satellite-based biomass monitoring products coming soon, including the Global Ecosystem Dynamics Investigation (GEDI) lidar instrument from NASA, and BIOMASS (a P-band synthetic aperture radar designed specifically to measure forest height and biomass) from ESA. Both products are expected to be live in time for early TFFF assessments.
} 
provide net biomass change, but not stocks. Currently, no globally consistent dataset exists that distinguishes between natural and plantation forests, although advances in the Hansen and GFW data are expected in the next few years to achieve this distinction (concurrent with establishment of the TFFF), and alternative satellite-based tree cover products are also becoming available. These developments will likely allow the TFFF to accurately and transparently mask out plantation areas and focus on natural forests from the start. ${ }^{36}$

For the purposes of modeling the peformance and allocation functions (below), Hansen et al. is used to estimate forest area change, and biomass estimates are from GFW-Climate, derived by combining Hansen et al. tree cover loss estimates with a carbon density map estimated by Baccini et al. ${ }^{37}$

\section{Country Participation}

There are over 100 tropical countries in the world, most of which have at least some forest area. A significant proportion of these countries have shown an interest in pay-forperformance forest conservation in the context of REDD+, with 67 unique countries engaged to some extent in either the Forest Carbon Partnership Facility or in the UNREDD program. There are several reasons the TFFF might limit the global offer to a subset of countries with tropical forests:

- The TFFF as proposed above would include a development objective within its core mission, and sovereign investor countries will likely seek to account for their support of forest countries through excess TFFF returns as climate finance and/or potentially ODA. As such, high-income economies should be excluded from the recipient pool.

- There will likely be fixed costs to the TFFF for each additional country included in the global offer. The cost of including countries with very small amounts of tropical forst area may exceed the value of their participation.

- Several countries — including China, Chile, and Argentina—are home to some tropical forests, but most of their forests are non-tropical. These countries should be excluded, as national-scale incentives based only on tropical forest area would likely be too small to significantly impact national land use planning, and could generate perverse outcomes such as leakage of forest loss from tropical areas to environmentally important non-tropical forests.

\footnotetext{
36 WRI's Global Forest Watch (GFW) is actively pursuing a major project to identify plantation forests. One of GFW's planned outputs will be a global plantation map, expected in the next few years. This could potentially be used to mask out plantation areas for the calculation and benchmarking of natural forest loss for the TFFF. Such an approach presents a trade-off: more complex data with the ability to make the distinction between natural vs plantation forests, or simpler data looking only at total forest cover without this distinction. At this point the former approach is recommended but both options may be considered.

37 This dataset was used in Zarin et al. (2016). It is available on through GFW on climate.globalforestwatch.org.
} 
- Other countries, like India, Bangladesh, Mexico, and Paraguay, have substantial forest area, some of which—but not most—is non-tropical. These countries should likely be included. However, investors may want to address these countries on a case-by-case basis to ensure that national-scale incentives are appropriate and to avoid perverse outcomes like deforestation leakage.

- A more limited set of countries may be included if the TFFF raises less than the target capital in order to maintain a politically relevant scale for payments to participants. The scope of participants could be narrowed based on a gap analysis of existing pay-for-performance commitments, to a specific region or income group, or to countries with ambitious deforestation reduction and reforestation commitments.

The TFFF's structure as a global offer using satellite-based global monitoring platforms suggests a very low barrier to entry by tropical forest countries. The "hands off" pay-forperformance approach proposed for the TFFF has also been attractive to tropical forest country representatives during initial consultations, compared to the common perception that existing REDD+ results-based instruments have a very high administrative burden including limitations on the use of payments. Furthermore, the small scale of existing finance for forests compared to the scale of need and mitigation opportunity suggest that forest countries would gain from participating in the TFFF even if they are actively engaged in other pay-for-performance modalities for REDD+ (as many of the larger tropical forest countries are). For these reasons, it is not expected that tropical forest countries would decline to participate in the TFFF, rather that they would choose to be included in a welldesigned global offer.

Recommendation: The TFFF should target tropical forest countries with significant tropical forest area that together represent at least 80 percent of global tropical forest area, and where 50 percent or more of the country's forests are tropical, excluding highincome countries. Smaller countries that have been significantly engaged in tropical forest protection may be considered for inclusion. Performance evaluation and monitoring should cover all natural forest areas of included countries, both tropical and non-tropical, to avoid perverse incentives.

Twenty-seven countries (Figure 5) were included in the TFFF modeling of peformance and allocation functions (below). They were selected by constructing a list of candidate tropical forest countries according to the recommendations above (e.g., excluding high-income countries, excluding China and countries where the majority of forests are non-tropical), then selecting them by area rank using 2000 tree canopy area at 10 percent cover threshold from Hansen et al. sufficient to exceed 80 percent of total forest area in candidate countries. Gabon would have been selected using this procedure if a higher tree cover threshold were applied, so it was included along with Paraguay, which was ranked above Gabon at 10 percent threshold, to avoid biasing the analysis based on the cover threshold used for selection. In this way, the sample included every country that would have been included as necessary to reach 80 percent of forest cover in tropical countries selected by any cover threshold from 10 percent up to 75 percent. Finally, Guyana and Liberia were added to 
expand the sample of countries with high forest cover and very low deforestation (Guyana) and very high deforestation (Liberia). Altogether, these 27 countries represent:

- 82-86 percent of year 2000 forest cover in tropical countries;

- 81-82.5 percent of gross forest cover loss from 2001-2014;

- $88-89$ percent of standing carbon stock.

This set of countries provide an illustration of the potential coverage of the TFFF, and illustrate that a very large proportion of tropical forest cover can be subject to incentives with a limited number of participants. For the purposes of modeling, this set includes moist and dry tropical forests, low to high historical deforestation rates, and all three major tropical forest zones.

Figure 5. Tree cover in countries selected for TFFF modeling (million ha)

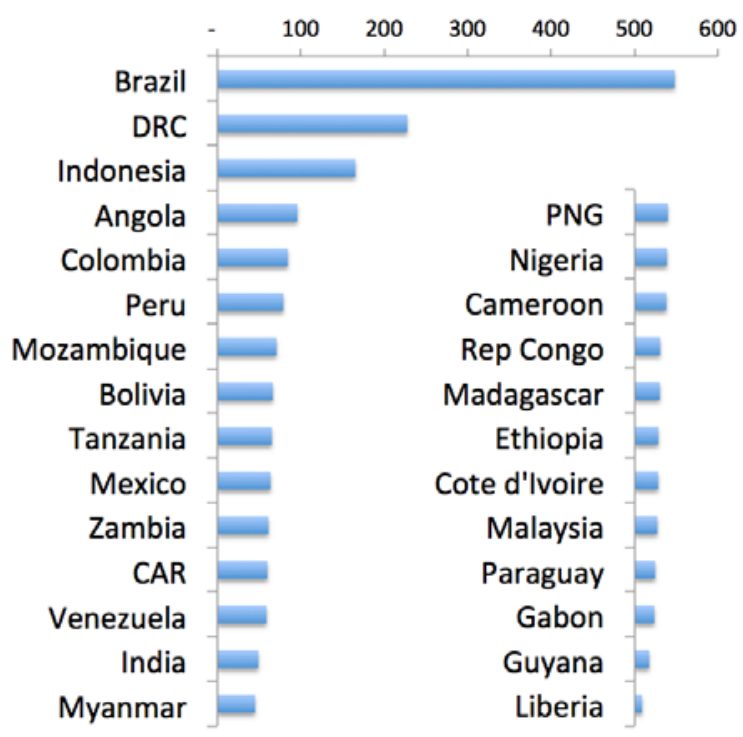

\section{Baselines (Reference Levels)}

While the TFFF as proposed will be complementary to REDD+ rather than being itself a REDD+ mechanism, much of the research on REDD+ reference levels is applicable to the performance assessment approach for the TFFF. Over a decade of research shows that "REDD + reference levels have profound implications for the climate effectiveness, cost efficiency, and distribution of REDD + finance among countries, involving tradeoffs between different interests and objectives." 38 This will be equally true for the implications of baselines or reference levels on the effectiveness, efficiency, and distribution of payments for the TFFF.

${ }^{38}$ Meridian Institute, 2009. 
First let us define terms. A reference level or baseline is simply a benchmark scenario against which future changes can be measured and potentially rewarded. ${ }^{39}$ In the context of REDD+, a distinction is made between business as usual (BAU) baselines, which are technical predictions of what would happen without REDD+, and crediting baselines, which are benchmarks against which a country's reductions are measured to receive "credit" under the UNFCCC REDD+ mechanism. ${ }^{40}$ An historical baseline is sometimes used as a proxy for a BAU baseline in the absence of modeling, assuming that past deforestation rates over a given period are the best proxy of future behavior. A compensation baseline may be distinct from a crediting baseline, for example if some forest sector emissions reductions are used by a country to receive credit for domestic commitments (e.g., Paris NDCs), while compensation is only sought from the international community for additional reductions beyond a more stringent compensation baseline. In this paper, we will use reference level to represent the level of performance a country must exceed to earn compensation from the TFFF, and historical baseline to mean an average observed net forest loss rate over some period of time. We also introduce the term "global benchmark" to mean a common pantropical measure of performance for all tropical forest countries.

In the context of REDD + , a baseline is usually constructed in relation to a specific type of activity (the scope). For example, a country may have one baseline for deforestation to assess performance on forest area loss or emissions from forest area loss, and a separate degradation baseline to assess performance on (and potentially receive payments for reducing) the loss of carbon in forests that remain forests. However, the TFFF would not be an activity-based instrument: it would ideally reward countries that both maintain and expand forests. This would include avoided deforestation (conversion of forest to nonforest), avoided forest degradation (loss of ecosystem services in forests remaining forests), and reforestation (new forest establishment), as all three processes impact forest ecosystem service provisioning. If the TFFF were to assess performance against forest biomass as a proxy for the amount of undervalued public goods provided by natural forests, irrespective of the activities that change forest biomass, only a single reference level for biomass loss is needed. The scope of the TFFF, while implicit, would thus cover all activities that impact this observed proxy.

Also relevant for considering reference levels is the context provided by forest transition theory. Alexander Mather coined the phrase "forest transition" to describe an observed pattern of forest cover loss, stabilization, and recovery over time as an area develops economically. ${ }^{41}$ A country with high forest cover and low deforestation rates (HFLD country) may see its deforestation rate accelerate (HFHD) and its forest cover diminish (LFHD) until forest cover stabilizes (LFLD) and possibly recovers. To the extent that this pattern holds, an historical baseline will underestimate BAU deforestation for HFLD

\footnotetext{
39 Parker et al., 2009.

40 Meridian Institute, 2009.

41 Mather (1992).
} 
countries at the early stages and overestimate it for LFHD and LFLD countries at late stages of this typical transition curve. ${ }^{42}$

Adjustments to historical deforestation rates are addressed in methodological guidance to forest countries on the establishment of reference levels for REDD+. Countries should establish reference levels "transparently taking into account historic data, and adjust for national circumstances..." 43 In part, such adjustments have been introduced to increase the effectiveness of the mechanism by constructing baselines that more accurately reflect BAU, either with broad adjustments in line with forest transition theory (using forest cover or income as proxies) or potentially by directly accounting for drivers of forest loss such agricultural prices or existing development plans. ${ }^{44}$ Addressing these divergences between historical deforestation rates and expected future rates can increase the effectiveness of a proposed reference level. 45

But effectiveness is not the only concern. Adjustments to reference levels have also been proposed to address national circumstances vis-à-vis equity, for example wealth adjustments or to account for forest countries' contributions to global climate effort. Finally, a range of models have proposed applying a global additionality adjustment to country reference levels to ensure that the sum of REDD+ baselines across all eligible countries does not exceed the expected BAU global loss or to ensure even deeper cuts.

Econometric models of REDD+ reference levels for deforestation ${ }^{46}$ have generated lessons that are applicable to setting reference levels for the TFFF's performance assessment. Most notably, they have shown:

- Stock-based approaches that assess performance based on total forest area or total carbon stock are much less effective than flow-based approaches based on change in forest area or carbon.

- Reference levels are important, but there is a much bigger difference between expected deforestation with or without payments than there is between expected deforestation with one versus another approach to setting baselines.

- The effectiveness of an instrument drops when country reference levels add up to more than the global BAU baseline. In other words, any upward adjustments to reference levels for HFLD countries should be counter-balanced by downward adjustments elsewhere.

- Reductions in forest loss increase as the global total of country reference levels becomes more stringent than global BAU, as long as there is sufficient finance

\footnotetext{
42 After Meridian Institute, 2009.

43 FCCC/CP/2009/11/Add.1, Decision 4/CP.15 Par.7

${ }^{44}$ Meridian Institute, 2009.

45 Busch et al. (2009); and Meridian Institute, 2009.

${ }^{46}$ In particular the OSIRIS model results as cited in Busch et al., 2009 and in Meridian Institute, 2009.
} 
available. Downward adjustments to reference levels over time could thus incentivize gradually deeper emission reductions.

- Reference levels that are set too high lead to payments for non-additional action, reducing effectiveness, while many countries decline to participate at all if reference levels are set too low (the rewards seem out of reach).

- Effectiveness and efficiency require a reference level approach that provides incentives to a broad range of countries, including those that have had both high and low historical deforestation.

- Setting reference levels to historical deforestation without any adjustment fails to provide an incentive for HFLD countries, and may cause their rates of forest loss to increase through non-participation and international leakage from HFHD countries that reduce losses.

Beyond the guidance provided by these "lessons learned" from models of REDD+ reference levels, the proposed structure of the TFFF imposes additional considerations. In particular, the same features of the TFFF that suggest use of globally-consistent satellite data rather country-based systems for forest monitoring - the global offer approach, zero-sum division of proceeds, and need to minimize overhead-also suggest that reference levels should not be subject to adjustments based on other types of country-based data, nor to negotiation by participants.

These considerations and the research on REDD + reference levels outlined above suggest the following recommendations:

- It is proposed that a single formula for reference levels and performance be applied consistently and transparently to all countries to ensure fair and non-biased allocation of shares in the facility, and to avoid lengthy negotiations or challenges.

- The primary measure of performance for the TFFF should be the rate of change in forest biomass from one period to the next. The rate of change is recommended rather than total stock in each period to maximize the economic efficiency of the TFFF as a global PES system; while biomass is recommended as the core underlying measure as it is expected to correlate well with a broad suite of forest public goods.

- Reference levels for the TFFF should be based on recent historical biomass loss rates in each country, to create an incentive for all participating countries to improve performance regardless of recent historical forest loss rates.

- The TFFF should adjust reference levels or performance scores towards a global benchmark. Such an adjustment will ensure that HFLD countries have an incentive to maintain forests; that investors will not be excessively exposed to criticism for payments to countries with high rates of forest loss; and that collective global progress will be assured. 
- The global benchmark should be set initially to the pan-tropical average net biomass loss rate, but should ratchet down over time consistent with zero net deforestation in 2030. Models suggest that this type of declining global benchmark would be economically efficient. A mixture of a tightening global benchmark and country historical averages will create an incentive for every country to maintain a "glide path" towards zero net deforestation. Countries with very low recent deforestation rates will receive incentive payments for maintaining these low levels, even if they don't decline substantially; while countries with high recent deforestation rates will have an incentive to bring them down immediately, but will be expected to improve quickly over time to continue receiving payments.

A proposed set of performance assessment formulas are outlined below for this recommended approach to setting reference levels for the TFFF, following an outline of an approach to awarding investment returns.

\section{Allocating Investment Returns}

Investment returns should be awarded in a way that maximizes their incentive function, while minimizing the financial risk to investor sponsors. It is proposed that the TFFF achieve this by applying the principles of "Cash on Delivery" — an aid idea ${ }^{47}$ developed at the Center for Global Development. Each year a proportion of the earnings of the TFFF will be allocated to tropical forest countries as shares in the facility. The share of earnings allocated to each country will be based on a formula that takes into account a country's performance as measured by its rate of forest biomass loss over an assessment period compared to a reference level, and the extent of the country's forests.

Why does extent matter? The value of reduced natural forest loss rates in a country depends not just on the change in rate, but also on the total amount of forest loss avoided.

Performance payments should therefore be larger for countries with large preserved forest stocks, given equal performance in reducing forest loss rates. In other words, payments to Brazil should be bigger than payments to Liberia even if both countries have the same starting deforestation rate (e.g., 1 percent per year of loss) and both cut that loss rate in half (to 0.5 percent per year).

It is proposed that the TFFF allocation formula achieve this by including a country weight (or size multiplier), based on the extent of forest as defined by either biomass, forest area, or some combination of the two. For example, if Brazil has 50 times as much forest biomass as Liberia, one might set its default allocation for a given level of performance (e.g., cutting loss in half from 0.3 percent per year to 0.15 percent per year) to be 50 times larger than Liberia's. However, the optimal weighting factor may not be as simple as this 1:1 ratio based on forest extent, for four primary reasons.

\footnotetext{
${ }^{47}$ See "Cash on Delivery Aid: FAQ." http://www.cgdev.org/page/cash-delivery-aid-faq
} 
First, there may be economies of scale that require less payment per unit of forest biomass preserved to induce change in a larger country (or conversely, there may be common fixed costs that make it more expensive to induce change in a smaller country). Second, the amount of forest area or forest biomass at high risk of deforestation — and thus the amount of payment necessary to forego that deforestation - is related to the fragmentation or compactness of a country's forests. Countries with much greater continuous forest areas are likely to have more interior and remote forest areas that are not subject to substantial deforestation pressure than those with fragmented forest areas with a large exposure and forest frontiers. Third, a larger proportion of the global and regional ecosystem service value of a country's forests will flow to other countries (rather than benefit domestic populations) for smaller countries, again suggesting that small-country payments will need to be proportionally larger per unit of performance. And finally, the ecosystem service value of a given amount of forest areas is likely higher in a smaller or less-forested country, as there is less substitutability with other forest areas-suggesting a higher value of forest ecosystem services to domestic populations and greater development benefit to maintaining these forest areas. Additional research is needed to investigate these differences and set an appropriate country weighting factor for the TFFF.

The allocation formula could include a weighting factor for global performance, with the goals of creating incentives for cooperation and avoiding huge payouts to one or two countries while the rest of the world's tropical forests disappear. If not all of the TFFF's excess earnings are allocated in a give performance assessment period, they could be held over for later allocations.

As discussed below, fund allocations may have greater impact on political decision making if countries are able to monetize them prior to disbursement, especially if the bulk of disbursements are made at towards the end of the fund's planned 20-year time span. Countries will be less able to monetize their fund allocations if the TFFF can "take back" allocations due to declining performance in later years, so only positive or zero allocations should be made. However, a strictly positive fund allocation formula risks providing a perverse incentive for high variability in loss rates: country could game the system by concentrating forest loss in fewer years, and still earn substantial rewards for high performance in other years. Two mechanisms are proposed to mitigate this risk: using a moving average of loss rates over 2 or 3 successive years for short term or annual performance assessments, and introducing a longer-term performance assessment and allocation cycle based on loss rates over a period of 5 or more years (or potentially over the lifetime of the mechanism) in additional to annual assessments and allocations.

\section{Delivering Rewards}

The TFFF faces a fundamental tradeoff in the timing of payouts.

A long investment horizon is necessary for the proposed endowment-like financial structure to succeed: it is almost certain that a fully-diversified portfolio will significantly outperform government bonds over the long term, but the fund value could dip below the capitalization in the near term. Early withdrawals and/or large regular withdrawals to make payouts to 
successful forest countries would significantly reduce the expected total value of all payouts from the fund (Figure 6), and would increase the risk that investors would not receive promised interest or lose some of their initial capital. Investors are not likely to participate if this risk is not managed carefully.

However, more immediate payouts may be more effective at generating results in some countries. The success of the TFFF depends on political will responding to a global offer of payments for performance, and the opportunity to earn a payout that only comes 10 or 20 years hence will likely be of little political relevance; politics is notoriously short-sighted. While there may be exceptions (for example, countries with existing performance-based payment agreements that only cover the near term may see a longer term horizon as a useful complement), it is well-understood that successfully earning shares of the TFFF will need to be made political relevant on a much shorter timeframe.

Figure 6. Expected total payout to forest countries of a USD 100 billion fund after 20 years at 5.65 percent annual return after costs, with different levels of planned annual payouts.

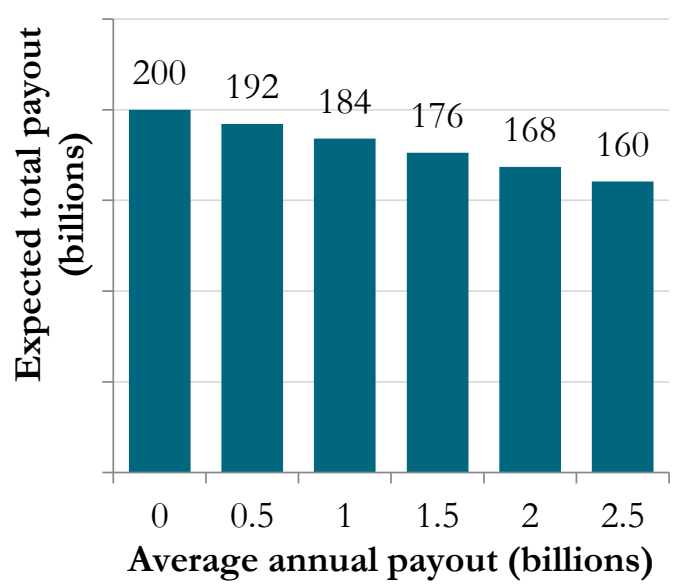

The TFFF will need to utilize some combination of approaches to address this tradeoff, reducing the risks for the long-term return while still providing some near-term incentive, including potentially:

- Allocating shares, not dollars: The TFFF will allocate shares of the total future excess value of the fund (beyond debt service and costs). For example, if the fund were established for a fixed 20-year period, it could divide the final excess returns into 2,000 shares and allocate 100 of them each year to countries based on performance. While the dollar value of shares would fluctuate from year-to-year, a current value and expected final value could be calculated any time the fund were "marked-tomarket." This approach will maximize the total earnings of the fund, and will decouple the interannual variability in returns from the annual performance allocations. 
- Monetizing earned shares more quickly: Short-term performance-based allocations of future rewards will be structured to allow countries to monetize earnings prior to final disbursal, for example by granting legal ownership of a proportion of final excess returns that could be used as collateral for bank loans, or as a complement to emerging instruments such as forest bonds or sustainable land bonds. ${ }^{48}$

- Early payouts: The TFFF may seek to distribute a small amount of the rewards earned by forest countries on an annual or biennial (every-other-year) basis. The risk to investor capital can be managed if only a small proportion of the total average expected return is withdrawn from the fund each year for payouts. Risk management would include operating the fund for several years prior to making any payouts, and by establishing market-based triggers for making or withholding shortterm payouts (for example, if the total fund value drops below a threshold).

What should the TFFF do with fund proceeds if few or no tropical forest countries perform sufficiently well? The "zero-sum" nature of the TFFF was discussed above, suggesting that the pool of proceeds would be divided between as many tropical forest countries as are successful, and greater success by one country will diminish the funding available to others. However, the TFFF should consider setting a maximum proportion of shares that can be earned each year by each country (for example, 2 to 3 times higher than their proportional share if all countries perform equally well), and should also designate an alternative for distributing proceeds if there are unallocated shares when the fund fully disperses (for example, to support global adaptation).

\section{Performance Assessment Timing}

A related question to the timing of rewards is the timing of performance assessments. Again there are a few key tradeoffs. More frequent performance assessments provide an opportunity for more immediate accountability—and for success to generate public rewards rapidly for political leaders. On the other hand, longer intervals between performance assessments will reduce uncertainty in the monitoring data and the potential for measurement errors, especially to the extent that biomass and forest area are monitored for regrowth as well as gross loss. There is also a moral hazard in allocating rewards to countries in the early years, especially if shares cannot be "clawed back" - which will be necessary if countries are to be able to monetize their shares up front. Longer performance assessment intervals may help to reduce this moral hazard. To balance these tradeoffs, we recommend that the TFFF consider a mixed schedule of annual or biennial performance assessments and longer-period (e.g., 5 years or more) assessments. The longer-period assessments could monitor change in forest cover and/or biomass just over the period since the last assessment, or from the first year of the fund to reward longer-term performance. More frequent assessments would be accompanied by smaller-than-proportional share allocations, and longer-period assessments would allocate the balance. For example, 40 percent of the shares could be allocated in annual assessments, with 15 percent allocated in years 5, 10, 15 and 20 .

${ }^{48}$ See, for example, Wheeler and Clenaghan (2018). 


\section{Conclusion}

With greater global integration, developing countries face increasing risks over which they have little or no control and which no one country has the incentive nor the ability to tackle on its own. Hence there is a need to provide additional international financing to developing countries to address those challenges.

The TFFF is a proposal to mobilize significant low cost resources which can be invested in private markets to generate a financial return for rewarding successful actions that contribute to achieving a global goal, reduced deforestation. We propose that the first such financing facility be established to generate resources to protect tropical forests due to the crisis of reversing deforestation trends. Without urgent action, there will be few remaining forests to protect. But if successful, this model would demonstrate a pathway to unlock a reliable and significantly enhanced flow of funds that could be used to address the SDGs and other critical global needs. The advantage of starting with forests is that modern satellite technology provides a relatively easy way to measure success unlike other outcomes at the domestic level which are more granular, subjective and expensive to measure. The high quality of satellite data allows shareholders in the TFFF to agree on what success means ex ante and to pool their resources to measure it. Each agency does not need to mobilize its own satellite system.

The role of the TFFF would be that of a tropical forest public goods facility, seeking to incentivize tropical forest protection and expansion for three objectives: 1) forest country economic development through greater provisioning of domestic ecosystem services; and greater provisioning of global public goods including 2) non-carbon goods such as biodiversity, and 3) climate protection services.

The proposed approach to measuring and rewarding performance for the TFFF benefits from more than a decade of research and development of the REDD+ mechanism, although with some difference that are driven in part by the sovereign wealth-like financial structure proposed to raise money. Monitoring would be achieved using the best available global satellite estimates of forest biomass and tree cover area. The scope of the TFFF would be natural tropical forests, and it would be designed to provide incentives for reduced deforestation and degradation as well as reforestation by monitoring net changes in both biomass and area.

By including only 27 tropical forest countries, the TFFF would provide incentives for protection of well over 80 percent of tropical forest area, and close to 90 percent of tropical forest biomass. To ensure that it operates efficiently to incentivize change across all participating countries, a mix of country historical averages and a "glide path" to zero net loss should define the reference levels. Shares of the final TFFF investment returns should be allocated to successful countries in proportion to their level of success and their forest extent, and mechanisms will be needed to allow countries to access the fund value more quickly. A mix of short-term and longer-term performance evaluations are recommended, to ensure that early successes are not substantially reversed.

Annex 1 details a set of specific mathematical formulas for the TFFF's performance assessment and allocation functions. 


\section{Annex 1: Proposed Performance Assessment and Allocation Functions}

The proposed performance score is a function of each country's forest biomass loss rate for the assessment period, a global benchmark starting at the global average loss rate and declining to near zero by 2030, and each country's average loss rate over the previous period of defined length.

Let $I_{t}$ be the amount of the TFFF's annual income in year $t$, and let $I_{i t}$ be the annual share of this income allocated to country $i$ in year $t$. Let $I_{\text {total }}$ be the TFFF's total income over the life of the fund (after debt service and expenses). Then, if all "excess" income is allocated to forest countries for performance-based payments (Eq 1 and 2):49

$$
\begin{gathered}
\text { Itotal }=\sum_{\mathrm{t}} \mathrm{I}_{\mathrm{t}} \\
\mathrm{I}_{\mathrm{t}}=\sum_{\mathrm{i}} \mathrm{I}_{\mathrm{it}}
\end{gathered}
$$

Rather than allocating income I, the TFFF may choose to allocate shares each year as a proportion of the final total income $I_{\text {totall }}$. For example, $100\left(S_{t}\right)$ shares out of a total 2000 $\left(S_{\text {total }}\right)$ shares could be distributed every year for 20 years. In this case, the actual value of a share would not be known until the fund is liquidated and income disbursed, although it could be estimated at any time. Under this approach, the equations are similar (Eq 1 and 2 alternate):

$$
\begin{gathered}
\mathrm{S}_{\text {total }}=\sum_{\mathrm{t}} \mathrm{S}_{\mathrm{t}} \\
\mathrm{S}_{\mathrm{t}}=\sum_{\mathrm{i}} \mathrm{I}_{\mathrm{it}}
\end{gathered}
$$

For country $i$ in year $t$, let:

$$
\begin{gathered}
F_{i t}=\text { forest biomass }{ }^{50} \text { in country } i \text { in year } t \\
L_{i t}=\text { forest biomass loss in country } i \text { in year } t \\
g_{i t}=\text { forest biomass loss rate in country } i \text { in year } t \\
\rho_{i t}=\text { country } i \text { 's share of global total forest biomass in year } t \text {, and }
\end{gathered}
$$

\footnotetext{
49 There may be reasons to relax the restrictions in Eq 1 and 2. For example, if most or all countries do poorly in a given year, the TFFF may not allocate all the income or shares from that year but rather withhold some to increase rewards for later improvements - creating an incentive for forest countries to work together. Another modification would be to allocate only a portion of each years' excess proceeds in annual performance reviews, while withholding the remainder to allocate for performance over longer periods.

50 As noted above, this measure would ideally be national level natural forest biomass. Each variable would represent a similar quantity in a carbon-based or a cover-based version of the model.
} 


$$
g_{t}=\text { global average forest biomass loss rate in year } t
$$

Then

$$
\begin{gathered}
\mathrm{L}_{\mathrm{it}}=\Delta \mathrm{F}_{\mathrm{it}}, \\
\mathrm{g}_{\mathrm{it}}=\frac{\left(\mathrm{F}_{\mathrm{it}}-\mathrm{F}_{\mathrm{i}(\mathrm{t}-1)}\right)}{\mathrm{F}_{\mathrm{i}(\mathrm{t}-1)}} \\
\rho_{\mathrm{it}}=\frac{\mathrm{F}_{\mathrm{it}}}{\mathrm{F}_{\mathrm{t}}}, \text { and } \\
\mathrm{g}_{\mathrm{t}}=\frac{\left(\mathrm{F}_{\mathrm{t}}-\mathrm{F}_{\mathrm{t}-1}\right)}{\mathrm{F}_{\mathrm{t}-1}}
\end{gathered}
$$

Note that the global average forest biomass loss rate in year $\mathrm{t}$ is a simple weighted average of national rates $(\mathrm{Eq} 7)$ :

$$
g_{t}=\sum_{i} g_{i t}\left(\frac{F_{i(t-1)}}{F_{(t-1)}}\right)
$$

For each country and year, define:

$$
\begin{array}{cc}
w_{i t}=\text { country } i \text { s forest extent weight in year } t, & \text { Eq } 8 \\
\pi_{i t}=\frac{I_{i t}}{I_{t}}=\text { country } i \text { s proportional share of allocations in year } t, & \text { Eq } 9 \\
\alpha_{i t}=\text { country } i \text { s raw performance score in year } t \text {, and } & \text { Eq } 10 \\
\beta_{i t}=\text { reference level for country } i \text { in year } t . & \text { Eq } 11
\end{array}
$$

In general, the country proportional allocations are a function of performance and weights, $\pi_{i t}=f\left(\alpha_{i t}, w_{i t}\right)$. The weights might simply be each country's proportional share $\left(\rho_{i t}\right)$ of global forest extent, but the division of proceeds between countries could take other forms as well—or even be based on a different measure entirely (such as relative forest cover rather than relative forest biomass, or adjusting for wealth to provide greater support for less developed countries). A power function weight was explored in simulations using:

$$
w_{\text {it }}=\left(\frac{\mathrm{F}_{\mathrm{it}}}{\mathrm{F}_{\mathrm{t}}}\right)^{\mathrm{r}} / \sum\left(\frac{\mathrm{F}_{\mathrm{it}}}{\mathrm{F}_{\mathrm{t}}}\right)^{\mathrm{r}}
$$

with values of $r$ between 0 and 1 . With $r=1$, the weight is simply $\rho_{i t}$. As $r$ decreases below 1 , the relative allocation to smaller countries increases relative to larger countries to account for the factors discussed above such as fixed costs and economies of scale. ${ }^{51}$

\footnotetext{
${ }^{51}$ Note that at $r=0$, every country's weight is equal.
} 
In general, country performance is a function of the reference level and the annual rate of loss, $\alpha_{i t}=f\left(\beta_{i t}, g_{i t}\right)$.

To set each country's historical reference level, define a set of $\mathrm{N}$ non-overlapping and successive measurement periods of years $\left(\mathrm{MP}_{k}\right)$ over which a reference level loss rate is constant, together covering the TFFF's full performance measurement period (year 1 to T). Also define a corresponding set of $\mathrm{N}$ reference periods such that each reference period includes a number of successive years $\left(\mathrm{RP}_{k}\right)$ of observed loss rates, such that all of the years in the reference period are earlier than the first year of the corresponding measurement period. Set each country's raw reference level in each measurement period to be the average deforestation rate over the corresponding baseline period, as either:

$$
\begin{gathered}
\text { algebraic mean: } \hat{\beta}_{i t, t \in M P_{k}}=\frac{\sum_{t \in R P_{k}} g_{i t}}{\left|R P_{k}\right|} \text {, or } \\
\text { geometric mean: } \hat{\beta}_{i t, t \in M P_{k}}=\left(\prod_{t \in R P_{k}}\left(1-g_{i t}\right)\right)^{\frac{1}{\left|R P_{k}\right|}}
\end{gathered}
$$

The performance measurement system currently applied in Brazil's Amazon Fund is a version of this model which uses a 5 -year measurement period and what might be called extending reference periods that all begin in the same year but include an additional 5 years of historical data in each successive measurement period. This contrasts with the original model for the Amazon Fund, which used rolling reference periods consisting of the 10 years prior to each successive 5 -year measurement period.

Option 1: For a national historical reference level approach, ${ }^{52}$ this historical average would be used as the country-specific reference level $\beta_{i t}$ and a performance score calculated as a function of forest loss rate and this benchmark. As in the Amazon Fund, these strictly historical reference levels could be adjusted slightly using a "non-increasing" rule, such that reference levels never go up: $\beta_{i j} \leq \beta_{i k}$ for all periods $j>k$.

However, as discussed above, more significant adjustments are recommended to a) incentivize HFLD to maintain low rates of loss in the face of development pressures and potential leakage from other countries that reduce loss; b) to maintain global additionality and avoid large payments to very high deforestation countries; and c) to create a "glidepath" toward zero net loss. We present three options for such adjustments.

Option 2: Averaging national historical levels and a global benchmark: Define a global benchmark $\beta_{t}$ to decline along a linear glide path from year 1 to year $T$. In year 1 , the benchmark is set to the previous year's (or previous $\mathrm{N}$-years') global average forest biomass loss rate. In year T, it is set to a small $\epsilon$ close to 0 .

52 Similar to a REDD+ reference level design in Santilli et al. (2005). 


$$
\begin{gathered}
\beta_{1}=g_{(\mathrm{t}-1), \mathrm{N}}=\frac{\left(\mathrm{F}_{\mathrm{t}-1}-\mathrm{F}_{\mathrm{t}-(\mathrm{N}-1)}\right)}{\mathrm{F}_{\mathrm{t}-(\mathrm{N}-1)}} \\
\beta_{\mathrm{T}}=\epsilon ; \text { and } \\
\beta_{\mathrm{t}}=\beta_{1}-\left(\frac{\mathrm{t}-1}{\mathrm{~T}-1}\right)\left(\beta_{1}-\epsilon\right)
\end{gathered}
$$

Country reference levels could then be adjusted towards this global benchmark in several different ways.

A simple weighted average could be applied to calculation of national reference levels: ${ }^{53}$

$$
\beta_{i t}=a \hat{\beta}_{i t}+(1-a) \beta_{t}
$$

For $a=0.5$, this would adjust every country's historical baseline halfway towards the global benchmark, bringing low deforestation countries' reference levels above their simple historical average and bringing high deforestation countries' levels down. Such a weighting could be applied only to countries with historical reference levels below the global average or the below the global benchmark and not above ${ }^{54}$ or only to countries with both low deforestation and high forest cover.

Rather than averaging country historical levels with a global benchmark, a "stock-flow" approach could use a "quota" system to adjust reference levels by allocating a proportion of the global historical average loss or of the global benchmark (say, 20 percent) to HFLD countries and adjusting reference levels accordingly, bringing down reference levels for high deforestation countries as needed to maintain global additionality. ${ }^{55}$

Option 3: National historical levels with a glidepath to zero: The model could dispense with the global benchmark entirely, and instead define each country's reference level in year 1 based on national historical loss and constructing a glidepath towards a near-zero target in year $\mathrm{T}$ as the reference level in later years. As above, adjustments would be needed to ensure participation by HFLD countries, and potentially to avoid overpayment to high loss countries and to maintain global additionality. This could be achieved relatively simply by adjusting year 1 reference levels away from the historical averages, with the same possible approaches as above.

From reference levels to country performance scores: In all three of the options outlined above, a country's performance over a period, as defined by biomass and/or area loss rate for the period, must be compared to the reference level for that period to calculate the performance score $\alpha_{i t}$.

\footnotetext{
53 Similar to the REDD+ reference level proposed by Strassburg et al (2009).

${ }^{54}$ Similar to the REDD+ reference level proposal by Mollicone et al (2007).

55 Similar to the REDD+ design proposed by Cattaneo (2008).
} 
We evaluate two versions of positive performance scores for forest loss below the reference level and 0 above:

$$
\begin{gathered}
\text { a distance: } \alpha_{i t}=\max \left(\left(\beta_{i t}-g_{i t}\right), 0\right) \text {, or } \\
\text { a ratio: } \alpha_{i t}=\max \left(\left(1-\frac{g_{i t}}{\beta_{i t}}\right), 0\right) .
\end{gathered}
$$

To avoid making payments to countries with excessively high loss rates, investors may want to impose a maximum rate of loss $\mu_{t}$ for each year, which countries must stay below to receive non-zero allocations. This could be achieved either using a constant maximum, or by setting a threshold at some fixed multiple of the global benchmark, $\mu_{t}=a * \beta_{t}$. Eq 16 would be adjusted accordingly.

The share of annual earnings allocated to each country in year $t=1$ would simply be its forest extent weight (Eq 8) times its performance score $\alpha_{i t}$, divided by a scaling factor $\sigma_{t}$ necessary to ensure that all income and no more is allocated in the year (Eq 17):

$$
\begin{aligned}
I_{i t} & =\frac{\alpha_{i t}}{\sigma_{t}} * w_{i t} * I_{t} \\
\sigma_{t} & =\sum_{i} \alpha_{i t} * w_{i t}
\end{aligned}
$$




\section{References}

Baccini, A., et al. 2017. "Tropical forests are a net carbon source based on aboveground measurements of gain and loss." Science, 358(6360), 230-234.

"From Billions to Trillions: Transforming Development Finance Post-2015 Financing for

Development: Multilateral Development Finance" prepared jointly by the African Development Bank, the Asian Development Bank, the European Bank for

Reconstruction and Development, the European Investment Bank, the Inter-American Development Bank, the International Monetary Fund, and the World Bank Group for the April 18, 2015 Development Committee meeting.

http://siteresources.worldbank.org/DEVCOMMINT/Documentation/23659446/DC2 015-0002(E)FinancingforDevelopment.pdf

Birdsall, N. and Diofasi, A. 2015. "Global Public Goods for Development: How Much and What For." Center for Global Development, 5.

Birdsall, N., Savedoff, W.D., Mahgoub, A. and Vyborny, K., 2012. Cash on delivery: a new approach to foreign aid. CGD Books.

Birdsall, N. and O. Barder. "Payments for Progress: A Hands-Off Approach to Foreign Aid." CGD Working Paper 102. Washington DC: Center for Global Development, 2006. https://www.cgdev.org/publication/payments-progress-hands-approach-foreignaid-working-paper-102

Birdsall, N., P.P. Kuczynski, and M. de Nevers. "Look to the Forests: How Performance Payments Can Slow Climate Change.” CGD Working Group Report. Washington DC: Center for Global Development, 2015. https://www.cgdev.org/publication/ft/lookforests-how-performance-payments-can-slow-climate-change

Birsdall, N., W. Savedoff. Cash on Delivery: A New Approach to Foreign Aid. Washington DC: Center for Global Development, 2010.

Buchner, B.K., P. Oliver, X. Wang, C. Carswell, C. Meattle, and F. Mazza, 2017. Global Landscape of Climate Finance 2017.

Busch, J., Strassburg, B., Cattaneo, A., Lubowski, R., Bruner, A., Rice, R., ... \& Boltz, F. (2009). Comparing climate and cost impacts of reference levels for reducing emissions from deforestation. Environmental Research Letters, 4(4), 044006

Cattaneo, A. (2008). How to Distribute REDD funds Across Countries. A Stock-Flow Mechanism. The Woods Hole Research Center, MA. Modeled in Meridian Institute, 2009.

Climate Focus. 2016. Progress on the New York Declaration on Forests: Eliminating Deforestation from the Production of Agricultural Commodities - Goal 2 Assessment Report. Prepared by Climate Focus in cooperation with the NYDF Assessment Coalition with support from the Climate and Land Use Alliance and the Tropical Forest Alliance 2020.

Climate Focus. 2017. Progress on the New York Declaration on Forests: Finance for Forests - Goals 8 and 9 Assessment Report. Prepared by Climate Focus in cooperation with the New York Declaration on Forest Assessment Partners with support from the Climate and Land Use Alliance. Available at: http://forestdeclaration.org/downloads/

Climate Law \& Policy, 2015. "Briefing Note: Unpacking the UNFCCC Framework for REDD+." Available at: https://www.climatelawandpolicy.com/ 
Collaborative Partnership for Forests, 2012. 2012 Study on Forest Financing. Available at: http://www.un.org/esa/forests/pdf/AGF_Study_July_2012.pdf

Donofrio, S., P. Rothrock, and J. Leonard, Supply Change: Tracking Corporate Commitments to Deforestation-free Supply Chains, 2017. Forest Trends, Washington, DC.

GCF/B.18/23 2 November 2017. https://www.greenclimate.fund/documents/20182/ 820027/ GCF B.18 23 - Decisions of the Board eighteenth meeting of the Board 30 September 2 October 2017.pdf/b55d8183-005c-4518-91dc$\underline{152113506766}$

GCF/B.17/02 23 June 2017. https://www.greenclimate.fund/documents/20182/751020/ GCF B.17 02 - Sixth Report of the Green Climate Fund to the Conference of the Parties to the United Nations Framework Convention on Climate Change.pdf Le630bc2c-d397-4431-b742-3b2508de64ac

Hamrick, K. and Gallant, M. 2017. Fertile Ground: State of Forest Carbon Finance 2017. Ecosystem Marketplace, W ashington, DC.

Hansen, M. C., P. V. Potapov, R. Moore, et al. 2013. "High-Resolution Global Maps of 21stCentury Forest Cover Change." Science 342 (15 November): 850-53.

Harris, N., Davis, C., Petersen, R., Goldman, L., Vary, L., Gibbes, S., Ciciarelli, C., forthcoming. Comparing global and national approaches to estimating deforestation rates in REDD+ countries. World Resources Institute, Washington, DC.

Mather, A. S. (1992). The forest transition. Area, 367-379.

Meridian Institute. 2009. "Reducing Emissions from Deforestation and Forest Degradation (REDD): An Options Assessment Report." Prepared for the Government of Norway, by Arild Angelsen, Sandra Brown, Cyril Loisel, Leo Peskett, Charlotte Streck, and Daniel Zarin. Available at: http://www.REDD-OAR.org.

Meridian Institute. 2011. "Modalities for REDD+ Reference Levels: Technical and Procedural Issues." Prepared for the Government of Norway, by Arild Angelsen, Doug Boucher, Sandra Brown, Valérie Merckx, Charlotte Streck, and Daniel Zarin. Available at: http://www.REDD-OAR.org.

Millennium Ecosystem Assessment (2005). Synthesis report. Island, Washington, DC.

Mollicone, D., Achard, F., Federici, S., Eva, H. D., Grassi, G., Belward, A., ... \& Schulze, E. D. (2007). An incentive mechanism for reducing emissions from conversion of intact and non-intact forests. Climatic Change, 83(4), 477-493.

Mullan, K. (2014). The value of forest ecosystem services to developing economies. Available at: https://www.cgdev.org/sites/default/files/CGD Climate Forest 6 Value Forest Ecosystems-Mullan.pdf

Norman, M. and Nakhooda, S. 2015. "The State of REDD+ Finance." CGD Working Paper 378 as updated in May 2015. Washington, DC: Center for Global Development. Available at: http://www.cgdev.org/publication/state-redd-finance-working-paper-378

Parker, C., Mitchell, A., Trivedi, M., Mardas, N., and Sosis, K. 2009. The Little REDD+ Book. Global Canopy Programme, Oxford, UK.

Santilli, M., Moutinho, P., Schwartzman, S., Nepstad, D., Curran, L., \& Nobre, C. (2005).

Tropical deforestation and the Kyoto Protocol. Climatic Change, 71(3), 267-276

Seymour, F., and J. Busch. Why Forests? Why Now? The Science, Economics, and Politics of Tropical Forests and Climate Change. Washington DC: Center for Global Development, 2016. 
Strassburg, B., Turner, R. K., Fisher, B., Schaeffer, R., \& Lovett, A. (2009). Reducing emissions from deforestation-The "combined incentives" mechanism and empirical simulations. Global Environmental Change, 19(2), 265-278.

Wheeler, P. and Clenaghan, S., 2018, Sustainable Land Bonds. The Nature Conservance and Climate Bonds Initiative. https://global.nature.org/content/sustainable-land-bondsreport

Wolosin, M. 2012. US Forest-Climate Assistance: An Asessment. Washington, DC. Resources for the Future. Available at: http://www.rff.org/research/publications/usforest-climate-assistance-assessment.

Zarin, D. J., Harris, N. L., Baccini, A., et al. 2016. "Can carbon emissions from tropical deforestation drop by $50 \%$ in 5 years?.” Global change biology, 22(4), 1336-1347. 